\title{
Testing a model for the delivery of emergency obstetric care and family planning services in the Bolivian public health system
}

Deborah L. Billings

Eliana Del Pozo

Hugo Arevalo

Follow this and additional works at: https://knowledgecommons.popcouncil.org/departments_sbsr-rh

Part of the Demography, Population, and Ecology Commons, Health Services Research Commons, and the International Public Health Commons

How does access to this work benefit you? Let us know!

\section{Recommended Citation}

Billings, Deborah L., Eliana Del Pozo, and Hugo Arevalo. 2003. "Testing a model for the delivery of emergency obstetric care and family planning services in the Bolivian public health system," FRONTIERS Final Report. Washington, DC: Population Council. 


\title{
Testing a Model for the Delivery of Emergency Obstetric Care and Family Planning Services in the Bolivian Public Health System
}

\author{
Deborah L. Billings \\ Senior Research Associate, Ipas \\ Eliana Del Pozo \\ Director, Ipas Bolivia \\ Hugo Arévalo \\ Research Coordinator, Consultant, Ipas
}

March 2003

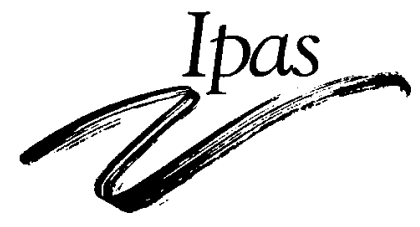

\section{(2) Population Council \\ Z Frontiers}

This study was funded by the U.S. AGENCY FOR INTERNATIONAL DEVELOPMENT (USAID) under the terms of Cooperative Agreement Number HRNA-00-98-00012-00 and Population Council Subagreement Number AI99.28A. The opinions expressed herein are those of the authors and do not necessarily reflect the view of USAID. 


\section{SUMMARY}

Unsafe abortion is a serious public health problem in Bolivia, accounting for up to 25 percent of maternal mortality. Postabortion care (PAC) was recognized as a priority public health action in Bolivia in 1994 in the country's preparatory statement for the ICPD. In 1999, PAC services, known as the "treatment of complications of hemorrhage during the first half of pregnancy," were included in Bolivia's revised national health plan, the Seguro Básico de Salud (SBS). Inclusion in the SBS makes PAC services free of charge to women and aims to: 1) increase women's access to services; 2) reduce the cost of service delivery and hospital length of stay; and 3) improve the quality of care. The operations research (OR) project carried out from May 1999 through August 2001 and summarized in this report was undertaken at the request of the Ministry of Health (MSPS) to help guide the improvement of PAC services as the SBS was implemented.

A non-experimental design with pre- and post-intervention measurements was implemented in three major maternity hospitals - Hospital de la Mujer (La Paz), Maternidad Percy Boland (Santa Cruz) and Hospital "Jaime Sánchez Porcel” (Sucre). Given the differences in infrastructure, size, and characteristics of the population served, comparisons are made between pre- and post-intervention results within but not between hospitals. A variety of data collection methods were used, including interviews, observations and record reviews. Data were collected from women treated for incomplete abortion, male partners (with women's consent and only in the Sucre site), and physicians. Three-month follow-up interviews were conducted with women in the Sucre site. The intervention consisted of re-organization of services to ambulatory care, PAC training, refresher training, and supportive supervision.

A Quality of Care Framework guided the design of the project, which focused on four main areas: 1) information and counseling (health status, uterine evacuation procedure, postabortion contraceptive services, including delivery of methods, care after leaving the hospital); 2) appropriate technologies and technical performance; 3) average cost of service delivery; and 4) potential for sustainability of services.

Improvements were made in the following areas: informing women of their health status after the uterine evacuation procedure, elements of the procedure itself (instrument to be used, pain control, possible risks), and informing women where to seek care in case of problems after leaving the hospital. However, women were not informed of the signs and symptoms of possible problems. Male partners did not receive information about the above items but were interested in learning more in order to help in the recovery process. High unmet need and desire for contraceptive services was documented but few women left the hospital with information about methods or with a method of their choice. Women leaving the Maternidad Percy Boland were most likely to leave with a contraceptive method. Results from three-month follow-up interviews in Sucre indicate that while women did not receive contraceptive methods before leaving the hospital, a significantly greater proportion of women returned to the hospital during the postintervention period for a method. In addition, fewer women were pregnant at the threemonth interview during the post- vs. pre-intervention phase and more women were using some form of contraception (modern, rhythm, or withdrawal). 
The use of Manual Vacuum Aspiration (MVA) by physicians was found to be as safe and effective as Sharp Curettage (SC) for the treatment of incomplete abortion. Despite barriers to use indicated by physicians, such as difficulties with pain management during the procedure, MVA use increased significantly in two of the three study hospitals over time.

Average cost of service delivery decreased overall during the post-intervention phase. Lowering average length of stay (ALOS) was an important factor in this trend. The largest decrease was seen in services re-structured as ambulatory care and employing MVA. The average cost of ambulatory services using SC also decreased but the drop was not as large. Average cost of service delivery was, in general, higher than the SBS reimbursement rate to hospitals. All women interviewed in both the pre- and postintervention periods stated that they had some out-of-pocket expenses related to hospital care.

The potential for sustainability for services exists and is dependent on continued political will, including follow-up of services regarding implementation of the newly published Norms and Procedures for Care of Hemorrhage during the First Half of Pregnancy, improvements in the procurement processes for MVA, and modifications in the reimbursement rates to hospitals. A great deal of work needs to be done in the areas of information, counseling and contraceptive service delivery before these services can be sustained. On a national level, work that has been initiated in primary and secondary levels of care needs to continue to make services more widely available to women and less costly to the health system. 


\section{CONTENTS}

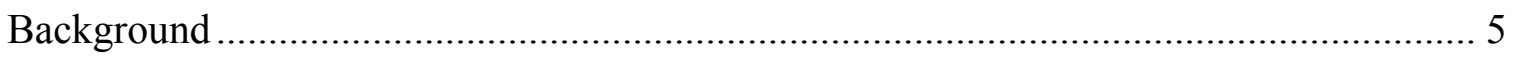

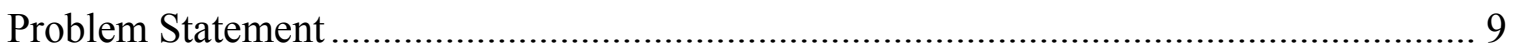

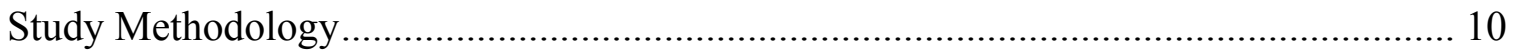

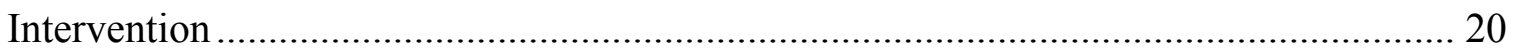

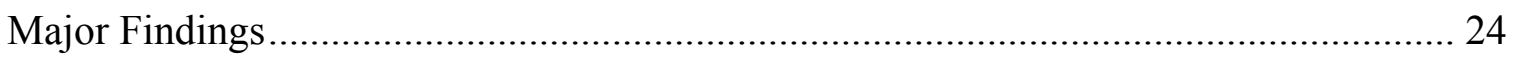

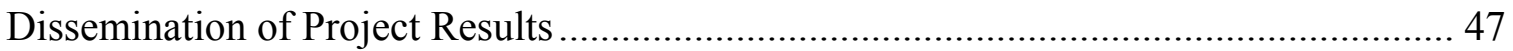

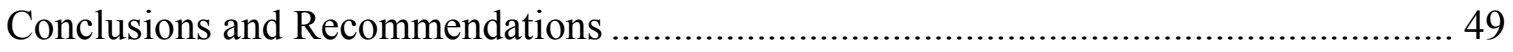

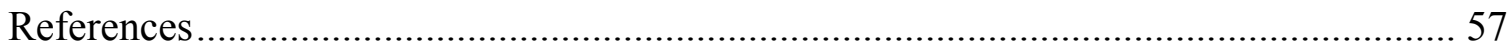




\begin{tabular}{ll} 
ABBREVIATIONS \\
ALOS & Average Length of Stay (in hospital) \\
CICAPA & Comité Interinstitucional Coordinador de Atención Postaborto \\
CRLP & Center for Reproductive Law and Policy \\
DFID & British Department for International Development \\
DHS & Demographic Health Survey \\
ICPD & International Conference on Population and Development \\
INE & Instituto Nacional de Estadística \\
IUD & Intrauterine Device \\
MMR & Maternal Mortality Ratio \\
MSPS & Ministerio de Salud y Previsión Social \\
MVA & Manual Vacuum Aspiration \\
NFP & Natural Family Planning \\
OR & Operations Research \\
PAC & Postabortion Care \\
SBS & Seguro Básico de Salud \\
SC & Sharp Curettage \\
SEDES & Servicio Departmental de Salud \\
STI & Sexually Transmitted Infection \\
UNAP & Unidad Nacional de Atención a las Personas \\
WHO & World Health Organization \\
\hline
\end{tabular}




\section{ACKNOWLEDGMENTS}

The project summarized in the following report is the result of the commitment of and collaboration among numerous people. The authors would like to recognize and thank the following individuals and organizations.

Ministerio de Salud y Previsión Social

Dr. Guillermo Cuentas, Minister of Health

Dr. Jaime Tellería, National Head of UNAP

Dr. Oscar Landivar, National Coordinator for Sexual and Reproductive Health

\section{Hospital Directors}

Dr. Abel Ruiz, Ex-Director, Hospital de La Mujer, La Paz

Dr. Ricardo Velarde, Ex-Director, Hospital de La Mujer, La Paz

Dr. David Asturizaga, Director Hospital de La Mujer, La Paz

Dr. Hugo César Chávez, Ex-Director, Instituto Municipal Maternológico "Percy Boland"

Santa Cruz

Dr. Luis Arnéz, Director, Instituto Municipal Maternológico "Percy Boland"

Santa Cruz

Dr. Edwin Subirana, Director, Hospital Gineco Obstétrico “Jaime Sánchez Pórcel”, Sucre

\section{PAC Trainers}

Dr. José David Ortiz Mariscal, Ipas Medical Director

Marta María Blandón, Director, Ipas Nicaragua

Dr. Malena Morales, Ipas Bolivia

Maria Eugenia López, Ipas Bolivia

Dr. Julio Aguilar, Chief of Ob/Gyn services and Coordinator of Reproductive Health and Family Planning Services at the Hospital Carrión in Lima, Peru

Nelly Moreno, Midwife and Coordinator of Family Planning Services in the Hospital María Auxiliadora in Lima, Peru

\section{Research Team}

Elizabeth Martínez, Coordinator of Data Coding and Entry, La Paz

Dr. Denisse Requena A., La Paz

Cinda Pérez, La Paz

Anel Chávez, La Paz

Vivian Jiménez (Coordinator in Post-Intervention Phase), Santa Cruz

Marisol Soliz Quiroz, Santa Cruz

Carmen Leticia Quiroz, Santa Cruz

Elizabeth Velasco, Santa Cruz

Ximena Arana (Coordinator), Sucre

Irma Tórrez V., Sucre

Zaida Grass U., Sucre

Dr. Jacqueline Calderón, Interviewer of trained physicians in all sites 
Production of Acciones en APA Bulletin Series and IEC Material

Wolfgang Kellert, Post Image

Gustavo Cardoso, CIMCA

Dr. Gladys Pozo, Director, Pathfinder International

Dr. Oscar Landivar, UNAP MSPS

Dr. Edward Ibáñez, Bolivian Society of Gynecology and Obstetrics

Population Council and USAID (FRONTIERS)

Dr. Emma Ottolenghi, FRONTIERS, Population Council

Dr. John Townsend, Director, FRONTIERS, Population Council

Dr. Ricardo Vernon, Director, FRONTIERS Latin America, Population Council

Dr. Judith Timyan, USAID Bolivia

Dr. Susan Brems, USAID Bolivia

Dr. Rocio Lara, USAID Bolivia

Dr. Sarah Harbison, USAID Washington D.C.

DFID

Desmond Whyms, Bolivia Representative

Ipas

Freddy Avila, Ipas Bolivia

Verónica Delgado, Ipas Bolivia

Gabriel Tórrez, Ipas Bolivia

Reynaldo Pérez, Ipas Bolivia

Janie Benson, Ipas (North Carolina)

Dr. Ronnie Johnson, Ipas (North Carolina)

Anne Corbett, Ipas (North Carolina)

Marian Abernathy, Ipas (North Carolina)

Norman Goco, Ipas (North Carolina)

Amanda Martínez, Ipas (North Carolina)

Suchitra Dutta, Ipas (North Carolina)

Jennifer Smith, Ipas (North Carolina)

Dr. Ricardo Pérez Cuevas, IMSS (Mexico), for his careful review of the paper. 


\section{BACKGROUND}

\section{Maternal Mortality and Unsafe Abortion in Bolivia}

Bolivia has one of the highest maternal mortality ratios (MMR) in Latin America, with an estimated 390 maternal deaths per 100,000 live births. Considerable differences emerge when comparing rural and urban maternal mortality, ranging from 262 for urban residents to 887 for women living in the rural highlands (altiplano) (INE, 1994; WHO/UNICEF 1996). High mortality is a product of structural factors, including poverty, discrimination and inequality throughout the country, and also is a consequence of barriers related to the cost of care, cultural and geographical accessibility to care, and poor medical attention or no attention at all related to obstetric emergencies.

The impact of unsafe abortion ${ }^{1}$ on Bolivian women's mortality and morbidity is documented through data derived from hospital records, thereby excluding women whose aftermath of abortion did not warrant seeking medical attention, women who did not access the formal medical system, and women who died from complications before seeking care or arriving at a health care facility. Underreporting notwithstanding, it is agreed that unsafe abortion has a significant detrimental impact on women's health, with the Ministry of Health and Social Welfare (MSPS) ${ }^{2}$ citing statistics that 25 percent of maternal mortality is attributable to complications of unsafe abortion (UNAP, 2001).

Approximately 60 percent of an estimated 285,000 pregnancies among Bolivian women in 1999 were unwanted (De la Gálvez Murillo, 2000). This is partially due to the low use of modern contraceptives accompanied by the high unmet need for contraceptive services among Bolivian women. According to the 1998 Demographic Health Survey (DHS), 31 percent of all women were using a contraceptive method at the time of the survey, with only 16 percent using a modern method. Many women choose abortion as an alternative to

\footnotetext{
1 "Unsafe abortion" is defined by the World Health Organization as a procedure for terminating an unwanted pregnancy either by persons lacking the necessary skills or in an environment lacking the minimal medical standards, or both (WHO, 1995).

${ }^{2}$ The Bolivian Ministry of Health has changed its name numerous times over the years. Thus, the current name, Ministerio de Salud y Prevision Social (MSPS), will be used throughout this document.
} 
continuing with an unwanted pregnancy. In the year 2000, an estimated 30,000 to 40,000 clandestine abortions were performed in Bolivia, many under unsafe conditions in part because of a highly restrictive legal environment and the inaccessibility of safe services (CRLP, 2001).

Within secondary and tertiary-level hospitals, health officials estimate that 47 to over 50 percent of hospital beds on gynecology wards are occupied by women admitted for abortion complications. Approximately 60 percent of total obstetric/gynecologic expenditures in public hospitals are incurred on the treatment of women with abortion complications (Cornejo, 1997; Rance, 1994; World Bank, 1994). Incomplete abortion is the most prevalent abortion-related complication treated in Bolivian hospitals.

\section{PAC in Bolivia}

Official government policy and discourse on the issue of abortion have changed significantly since 1989, when reproductive health was officially recognized for the first time as distinct from maternal health through the establishment of a national reproductive health program. In that same year, Bolivia witnessed the first public debate on abortion in the form of a seminar sponsored by the MSPS. Reproductive health services, including contraceptive services, were made available as part of national public health services for the first time in 1992.

In 1994, the treatment of complications resulting from unsafe abortion was prioritized as a public health issue and presented in Bolivia's Declaration of Principles on Population and Sustainable Development, developed in preparation for the International Conference on Population and Development (ICPD) (Ministerio de Desarrollo Humano, 1994). In this policy document, reducing the negative consequences of unsafe abortion and humanizing treatment for women experiencing abortion complications were established as strategies necessary to reach the goal of decreasing maternal mortality and morbidity. 
Since ICPD, the concept of postabortion care (PAC) has been put into practice throughout the world as one way to strengthen the capacity of health systems to provide comprehensive care to women treated for abortion complications.

Throughout the 1990s, PAC has been presented as including three essential elements (Greenslade et al., 1993) :

- emergency treatment services for abortion complications;

- postabortion family planning (contraceptive) services; and

- linkages between emergency treatment and other reproductive health services.

The delivery of high quality, humane care is key to the success of such services. This includes the provision of comprehensive information and counseling about women's health and care in a manner that is respectful of women's rights, paying particular attention to their needs, desires and decision-making processes.

With its commitment to create high quality PAC services in the public sector, the Bolivian MSPS requested a series of studies and actions to be carried out from 1994 through 1998 with the technical assistance of various international organizations, most notably Ipas and the Population Council. Actions included awareness-raising workshops aimed at health care providers and policymakers that focused on interventions and solutions that could address the problem of unsafe abortion and the creation of the Inter-institutional Coordinating Committee for Postabortion Care (Comité Interinstitucional Coordinador de Atención Postaborto, CICAPA) (Arze and Del Pozo, 1998).

Recommendations of PAC studies conducted throughout the late 1990's in Bolivian public sector hospitals highlighted that the quality of care needed to be improved. Key areas that needed to be strengthened were: humanizing the care offered to women, providing women with complete information throughout the process of care, including information about their health status and the procedures they experience, counseling about contraceptive options in accordance with women's needs and reproductive intentions, and providing women with contraceptive methods when so desired before they leave the hospital (Rance 1997, 1999a, 1999b). 
Researchers from one project (Díaz et al., 1999a, 1999b) conducted in the same three hospitals included in this present study, but using different data collection techniques, concluded that quality of care and contraceptive acceptance could be improved when the following conditions existed: highly motivated staff trained to improve their communication skills and to provide compassionate care, who were then provided with continuous support from administrative authorities in the health system, ongoing technical assistance, refresher training and continuous supervision. How the services could be maintained once the project resources were no longer available was an important question for the project team.

Results from other studies showed the average cost of PAC service delivery to be relatively high and primarily related to hospital length of stay, presenting potential challenges to the sustainability of services that should be offered free of charge to women (Friedman et al., 1999). Lastly, research findings indicated a high degree of interest among health care providers and policymakers to introduce Manual Vacuum Aspiration (MVA) formally into the public health system, providing an alternative to Sharp Curettage (SC) in the treatment of incomplete abortion (Córdova, 1997).

In addition, the results from a PAC operations research (OR) project conducted in 1997 in Peru influenced the direction taken by the MSPS in its directives on implementing PAC services in Bolivia. Changes in PAC services in the Hospital Carrión in Lima included reorganization of services to ambulatory care, introduction of MVA for the treatment of incomplete abortion, and linkages between emergency care and contraceptive services. Subsequent to the intervention, hospital stay for women treated for abortion complications decreased from 33 hours to approximately 6 hours, with an associated 62 percent decrease in the average cost of services to the hospital from \$US119 to \$US45 per patient. The percentage of women treated with MVA rose from zero to 91 percent and the proportion of women receiving information about the uterine evacuation procedure and about contraceptive methods significantly increased after the intervention (Benson et al., 1998). These results were illustrated to Bolivian hospital directors and MSPS officials during a study tour organized by Ipas to tertiary-level facilities in Lima, Peru in January 1999. 
Participants returned to Bolivia with a greater commitment to strengthening PAC services and introducing MVA in the public health sector.

In March 1999, the Bolivian MSPS initiated the Seguro Básico de Salud (SBS) national health plan, an expansion of a previous plan implemented throughout the country in public health care facilities. ${ }^{3}$ One of the significant differences between the previous plan and the SBS is that the latter covers the costs of treatment of incomplete abortion, known in the SBS as "the treatment of complications of hemorrhage during the first half of pregnancy." The three main objectives of this coverage, formalized in the March 1999 Ministerial Resolution No. 0133 (MSPS, 1999), were to:

- increase women's access to emergency care services for abortion complications by making them free of charge;

- reduce the cost of service delivery and hospital length of stay by introducing MVA for the treatment of incomplete abortion ${ }^{4}$; and

- improve the quality of care offered to women treated for abortion complications.

The OR project summarized in this report was carried out in direct response to a request made by the MSPS for assistance in guiding the improvement of PAC services as the SBS was implemented.

\section{PROBLEM STATEMENT}

The focus of this FRONTIERS PAC OR project was to measure the impact of a service delivery intervention on the: 1) quality of PAC services offered to women, including information and counseling, the effectiveness of postabortion contraceptive services, and the quality of clinical care; and 2) women's length of stay in the hospital and the cost of service delivery. The cost of care to women was also examined, given that within the SBS services should be free of charge.

\footnotetext{
${ }^{3}$ The previous plan was known as the Seguro Nacional de Maternidad y Niñez (SNMN or National MotherChild Insurance)

${ }^{4}$ Sharp curettage was the method officially used for the treatment of incomplete abortion in public sector hospitals until the initiation of the FRONTIERS-supported OR project described in this report.
} 
In addition to addressing the substantive interests outlined above, this project explored an area that, to date, has been relatively undocumented - the role of men/male partners in postabortion care and in woman's subsequent recovery and contraceptive behavior. Given the relative dearth of information regarding these themes, descriptive data were collected that can be used to generate discussion and inform ways in which PAC service delivery might be modified to ensure that women's health needs are met.

\section{STUDY METHODOLOGY}

The main objective of this study was to document the impact of a PAC service delivery intervention in three tertiary-level maternity hospitals in Bolivia. Variables and hypotheses of interest are outlined below.

The project was conducted by Ipas Bolivia, in collaboration with the Bolivian Ministry of Health and Social Welfare (MSPS), from May 1999 through August 2001. Research and service delivery interventions were carried out in three of Bolivia's main maternity hospitals: the Hospital de la Mujer in La Paz; the Maternidad Percy Boland in Santa Cruz; and the Hospital "Jaime Sánchez Porcel” in Sucre.

Hospital de la Mujer: Located in the capital city of Bolivia's most populous Department of La Paz (pop. 2,406,368), which has 470 health posts and centers, 39 district hospitals and 24 general and specialized hospitals, of which the Hospital de la Mujer is one. Seventy-seven percent of all hospital beds in the Department are concentrated in the city of La Paz. In 1996, an estimated 13\% of maternal mortality was due to unsafe abortion in the Department; only $18 \%$ of currently married women were using a modern contraceptive method and $23 \%$ of women of reproductive age had unmet need for contraceptive services, according to the 1998 DHS. A significant percentage of the population is indigenous and lives dispersed among 20 provinces and 75 municipalities. Other studies have documented the reluctance of many indigenous women to seek emergency care in public hospitals and health centers where they risk discrimination and the possibility of legal sanctions, thereby presenting challenges to fully attending to the needs of these women (Rance 1999).

Maternidad Percy Boland: Located in the city of Santa Cruz de la Sierra, in the Department of Santa Cruz, Bolivia's second largest department (pop. 1,812,523). In 19981999 , an estimated $14 \%$ of maternal mortality was due to unsafe abortion. Thirty-nine percent of currently married women were using a modern contraceptive method and $20 \%$ of women of reproductive age had unmet need for contraceptive services, according to the 1998 DHS. More than $80 \%$ of the population live in urban areas throughout the Department. The Department has 393 health posts and centers, 39 district hospitals and 19 
general and specialized hospitals, of which the Maternidad Percy Boland is one. Percy Boland is one of Bolivia's main teaching hospitals, with 154 beds and an average of 1000 births per month.

Hospital “Jaime Sánchez Porcel”: Located in the country's capital city, Sucre, in the fifth most populous Department of Chuquisaca (pop. 500,000), where $60 \%$ of the population live in rural areas, most often in communities of less than 2,000 people. The Department has 242 health posts and centers, 12 district hospitals and 8 general and specialized hospitals, of which the "Jaime Sánchez Porcel" is one. In 1998, an estimated 5\% of maternal mortality was due to unsafe abortion. Only $18 \%$ of currently married women were using a modern contraceptive method and 39\% of women of reproductive age had unmet need for contraceptive services, according to the 1998 DHS. Sucre is home to a large and well-known university that receives students from all over the country. Thus, there is a high concentration of adolescents living away from their families in Sucre. The first and only legal abortion carried out to date in Bolivia was conducted in the Hospital "Jaime Sánchez Porcel" in 1998 with a 14-year old young woman who had been raped by her stepfather (Domínguez, 1999).

The Population Council's FRONTIERS Program supported the research component in all three hospitals as well as the intervention in Sucre, while funds obtained by Ipas from the British Department for International Development (DFID) were used for the intervention component in La Paz and Santa Cruz.

Overall, the project was built upon implementation of a quality of care framework used and accepted by PAC programs around the world (Leonard and Winkler, 1991) (see Figure 1). 


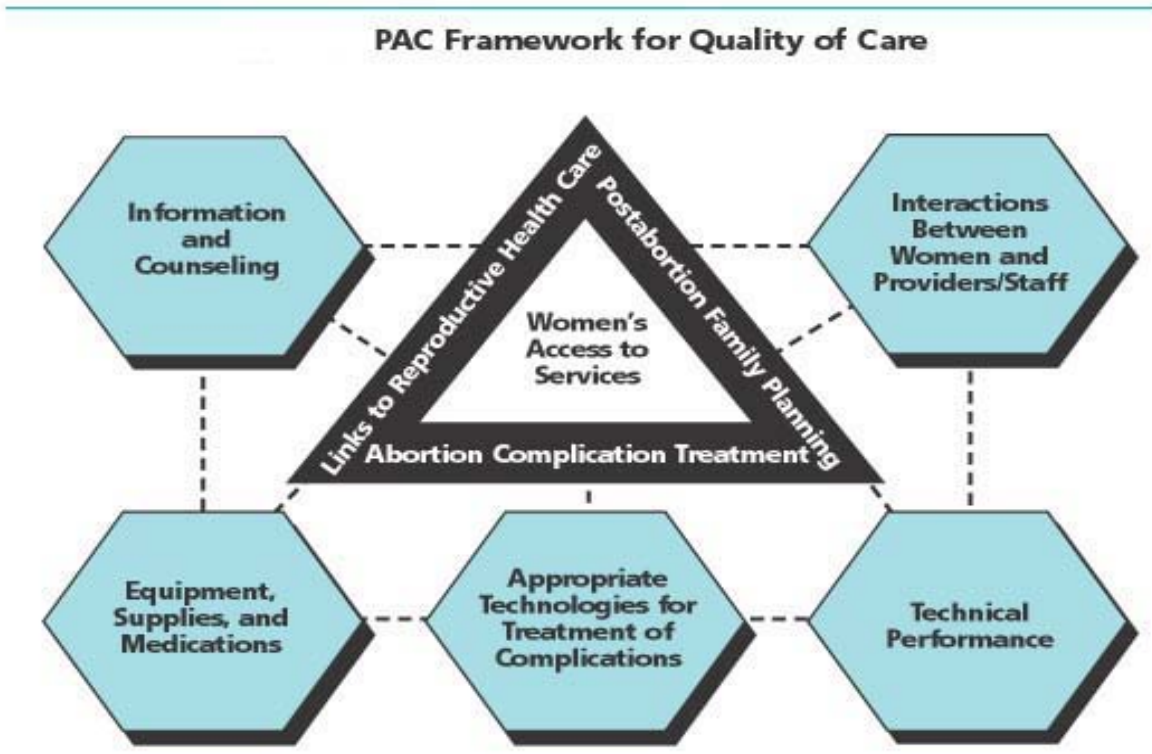

\section{Information and Counseling}

Information and counseling for women treated for abortion complications are key to ensuring that they leave the hospital more informed about and conscious of their state of health and with the confidence that health care providers are available as resources to support them with their health needs. In addition, information and counseling services help women return to their homes with a greater ability to care for their health, prevent future unwanted pregnancies, and seek professional care in the future.

International consensus among researchers, health care providers, and policymakers regarding the basic information that should be provided to women during PAC services was reached and outlined during the early stages of PAC work (Wolf and Benson, 1994).

Information and counseling about the following issues should be included in PAC services:

- Woman's health status at entry to the hospital and after the procedure;

- Possible risks and complications, as well as pain control, during the uterine evacuation procedure;

- Signs and symptoms of possible health problems after discharge from the hospital and where to seek health care services in case of problems;

- Recommendations regarding health care after returning home; 
- Women's/couple's future reproductive plans and desires; and

- Essential information on contraceptive methods and services, according to a woman's/ the couple's reproductive plans and desires.

For many women, the time during which they are being treated for abortion complications provides a unique opportunity to reach them (and their partners) with contraceptive information and services, as well as information about the prevention of sexually transmitted infections (STIs). All health care personnel have a responsibility to be informed about the methods available and to provide information and counseling. According to the MSPS guidelines for contraceptive service provision, three basic areas need to be covered (UNAP 2000):

- That women can become pregnant once again before the return of their next menstrual period

- That safe and effective contraceptive methods exist to prevent or space future pregnancies

- Where and how to obtain sexual and reproductive health services, including contraceptive methods.

The provision of these basic elements of information and counseling were examined in the project, in particular whether the service delivery intervention made a positive impact on service provision. Outlined below are the four main areas of analysis: health status, uterine evacuation procedure, care in home, and contraceptive services.

\section{Health Status}

Hypothesis:

- Significantly more women with abortion complications will receive information about their health status, upon entry to the hospital as well as after the uterine evacuation procedure, in the post-intervention period, relative to the pre-intervention period.

\section{Uterine Evacuation Procedure}

Hypothesis:

- Significantly more women with abortion complications will receive information about the uterine evacuation procedure- instrument to be used, pain control, possible risks and complications- in the post-intervention period, relative to the pre-intervention period.

\section{Postabortion Contraceptive Services}

Hypotheses:

- Significantly more women treated for abortion complications will receive postabortion contraceptive counseling after emergency treatment in the post-intervention period, relative to the pre-intervention period. 
- Of the women receiving counseling, a significantly higher proportion will accept a contraceptive method in accordance with their reproductive intentions in the postintervention period, relative to the pre-intervention period.

- Of the women accepting a contraceptive method prior to discharge from the hospital, a significantly higher proportion will continue to use a contraceptive method 90 days after discharge from the hospital, in accordance with their reproductive intentions in the post-intervention period, relative to the pre-intervention period (tested only in Sucre).

\section{Care after Leaving the Hospital}

Hypothesis:

- Significantly more women with abortion complications will receive information about how to care for themselves once at home and about signs and symptoms of possible complications in the post-intervention period, relative to the pre-intervention period.

\section{Appropriate Technologies and Providers' MVA Skills}

An important component of this project is the official introduction of a new technologyMVA- for the treatment of incomplete abortion into Bolivia's public sector hospitals. Physicians' level of experience with MVA varies across hospitals, with most having more extensive experience with SC. As such, the use, safety, and effectiveness of MVA and SC are examined in this study.

Hypotheses:

- MVA for the treatment of incomplete abortion (uterine size $\leq 14$ weeks) will be used and accepted by physicians during the post-intervention period.

- Physicians' use of MVA will be as safe and effective as their use of SC.

\section{Average Cost of PAC Services}

As defined in the SBS hospital reimbursement scheme, treatment of incomplete abortion with MVA is linked with ambulatory care while treatment with SC continues to be linked with in-patient care. In addition, the SBS, implemented in March 1999, defines PAC services as free-of-charge to women.

\section{Hypotheses:}

- Hospital stay for women treated with MVA will decrease significantly from the preintervention to the post-intervention period, given the reorganization of services from in-patient to ambulatory care.

- Hospital stay is the most important component of care related to decreasing the cost of service delivery to the hospital.

- Services provided with MVA in an ambulatory manner are, on average, less expensive to the hospital than services provided with $\mathrm{SC}$ with hospitalization. 
- Throughout the project, women do not pay for PAC services.

\section{Potential for Sustainable PAC Services}

One central aim of this project is to introduce a service delivery intervention that will be sustainable over time with the resources provided by the SBS.

\section{Hypothesis:}

- Modifications made in PAC services will contribute positively toward making them sustainable in the hospitals for the period during which the SBS is in effect.

\section{Study Designs}

While a pre-post control group experimental design was desired to test the study's hypotheses, data collected during the 1998 assessment of PAC services established that few hospitals had the caseload necessary to reach the desired sample sizes for this current study (see "Study Site Criteria"). These hospitals were different in terms of infrastructure, staff composition and the characteristics of the women that receive care, thereby making the designation of a control site difficult. Thus, a non-experimental design using pre- and postintervention measurements was used.

The three hospital sites included in the study were chosen by the project team, including the MSPS's National Coordinator for Sexual and Reproductive Health and USAID/Bolivia staff, for two major reasons. First, they are the largest maternity hospitals in the country with the highest caseloads of women treated for incomplete abortion. ${ }^{5}$ Second, resources had already been dedicated to PAC work in these hospitals and this current study provided an opportunity to examine the continuation of service delivery (see previous work by Díaz et al., 1999a, 1999b). Interest expressed by hospital directors in participating in the project was an important factor for gaining full access to facility records, staff and patients. Each hospital is located in a distinct area of the country, where geography and population characteristics differ in important ways. Thus, in the Major Findings section comparisons are not made between hospitals but rather between the pre- and post-intervention periods within each hospital.

\footnotetext{
${ }^{5}$ Caseloads: Maternidad Percy Boland: approximately 1400 per year; Hospital "Jaime Sánchez Porcel”: approximately 400 per year; Hospital de la Mujer: approximately 260 per year.
} 
The same study design was used in the Hospital de la Mujer and the Maternidad Percy Boland since, upon returning from the study tour in Peru, the directors of the first two hospitals wanted to initiate training in PAC with MVA immediately, thereby leaving little time for pre-intervention data collection. A different study design was employed in the Hospital "Jaime Sánchez Porcel" since the Director of the Hospital agreed to wait for the implementation of the intervention, allowing the research team more time to conduct data collection during the pre- and post-intervention phases of the project. In the Hospital de la Mujer and the Maternidad Percy Boland, pre- and post-intervention data collection took place during two 2-month periods (See Figure 2).

Figure 2: Two Hospitals - La Paz and Santa Cruz

Time

Intervention Site

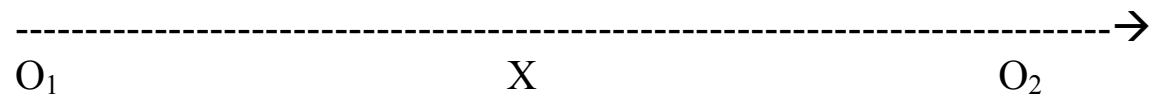

$\mathrm{O}_{1}$ Exit interviews with women and providers, observation of care, clinical record form (2 months)

$\mathrm{X}$ Intervention: Re-organization of services, core and refresher trainings, implementation of services, supportive supervision (12-13 months)

$\mathrm{O}_{2}$ Exit interviews with women and providers, observation of care, clinical record form (2 months)

In the Hospital "Jaime Sánchez Porcel” pre- and post-intervention data collection took place during two 8-month periods. This includes the time during which follow-up interviews with women 90 days after their discharge from the hospital were conducted.

The last three months of follow-up data collection with women interviewed in the hospital during the pre-intervention period overlapped, in part, with the start-up of intervention activities. However, the intervention had no impact on the responses of women interviewed during this follow-up period (See Figure 3).

\section{Figure 3: Third Hospital - Sucre}

\section{Time}

Intervention Site

Time
$\mathrm{O}_{1} \mathrm{O}_{2}$
$\mathrm{X}$

$\mathrm{O}_{1} \quad$ Exit interviews with women, male partners, and providers, observation of care, clinical record form (4 months)

$\mathrm{O}_{2} \quad$ 90-day follow-up interviews with women (4 months)

$\mathrm{X}$ Intervention: Re-organization of services, core and refresher trainings, implementation of services, supportive supervision (12 months)

$\mathrm{O}_{3} \quad$ Exit interviews with women, male partners, and providers, observation of care, clinical record form (4 months)

$\mathrm{O}_{4} \quad$ 90-day follow-up interviews with women (4 months) 


\section{Data Collection Methods}

The criteria for selection of women participating in the study in all of the hospitals included:

- admission for treatment of incomplete abortion (complications related to bleeding in the first trimester of pregnancy) unaccompanied by complications such as shock, sepsis or uterine perforation, with uterine size equivalent to or less than 14 weeks gestation;

- informed consent provided to the observer and/or interviewer for participation in the study;

In the case of Sucre, all women fulfilling these criteria and treated in the study hospital over a continuous four-month period were asked to also participate in the 3-month follow-up interview.

\section{Observation of care and cost of services provided to women treated for incomplete} abortion from admission to discharge (All three hospitals)

Women were observed throughout the process of care to measure: the general quality of care of services and provider compliance with appropriate clinical practice, the time spent by women in the hospital, the time spent with women by different types of staff, and the amounts and types of medications and supplies used during the woman's care. Two different observation guides were used to collect data used to evaluate quality of care and cost of service delivery. Information on personnel salaries, the cost of different medications, and overhead were obtained from hospital and Ministry records.

Exit and follow-up interviews with women treated for incomplete abortion: (Exit conducted at all three hospitals; Follow-up conducted in Hospital “Jaime Sánchez. Porcel" in Sucre only)

Prior to discharge from the hospital, all women fulfilling the study criteria participated in an interview in which the effectiveness of services, the overall quality of care, and specific needs relative to the woman's reproductive intentions were documented. In the Hospital "Jaime Sánchez Porcel," all women interviewed in the study prior to their exit from the hospital were asked whether they would be willing to be re-interviewed, in a location of their choice, three months after discharge from the hospital. Women who responded affirmatively were contacted in a manner they indicated as appropriate - by phone, home visit, or return to the hospital at an appointed time. At the time of re-contact, women were 
once again asked of their willingness to participate in the study through the application of a pre-designed informed consent form. Protection of women's confidentiality and privacy was strictly observed during follow-up.

\section{Clinical Record Form (All three hospitals)}

The clinical record form was filled out by providers after performing the uterine evacuation procedure. It included detailed information on each woman's clinical condition, the results of the procedure (including any complications experienced and whether the uterine evacuation was complete), and pain control medications used during the procedure.

Interviews and self-administered questionnaires with physicians (All three hospitals) During the pre-intervention period, physicians who were to participate in the PAC training were asked to respond to a brief self-administered questionnaire; a similar questionnaire was answered by physicians who participated in the PAC training during the postintervention period. In addition, physicians were also interviewed about the PAC services they offered. Objectives of these instruments were to obtain physician's perspectives on the quality of services, their acceptance of changes in the organization of services; and their acceptance and use of MVA and SC.

\section{Hospital Record Review (All three hospitals)}

Hospital records were reviewed to determine the extent of use of MVA and SC for the treatment of incomplete abortion during the post-intervention period.

\section{Interviews with male partners present at the hospital (Conducted at Hospital "Jaime} Sánchez Porcel" in Sucre only)

Interviews with male partners focused on their role in the abortion experience, their perspectives toward contraceptive use within the couple, including plans for the postabortion period, their understanding of the woman's health status, possible complications and factors related to return to normal life activities, and the forms of social support that they would offer once the couple returned to their home.

Criteria for Inclusion of Male Partner in the Study

- Informed consent of the woman to have her partner interviewed;

- Informed consent of the male partner;

- Male partner present at the hospital at the time of the woman's discharge. 
All male partners fulfilling the criteria outlined above were interviewed prior to the woman leaving the hospital but after she completed her exit interview. No attempts were made to re-interview male partners at the 90-day follow-up.

\section{Sample Included in the Study}

Non-probability purposive sampling was used to identify the women, their partners and health care providers included in the study. All subjects fulfilling the study criteria and providing their informed consent during the field periods defined for each hospital were included in the study. The table in Appendix A outlines the data collected throughout the project (May 1999 - August 2001)

The expected number of at least 50 interviews with women in the hospitals and 15 observations of care was obtained. However, after data cleaning some interviews with women treated in the Hospital de la Mujer during the pre-intervention period were deleted, leaving information from only 48 interviews. The research team in Sucre was successful in conducting follow-up interviews with women at the three-month post-exit period, particularly given that women lived in geographically disperse areas requiring significant travel either on the part of the women, if she returned to the hospital, or for the interviewer when the interview was conducted in the woman's home. In the original proposal, a 45 percent success rate during follow-up was proposed. ${ }^{6}$ The research team reached 64 percent of all women interviewed in the hospital during the pre-intervention phase and 71 percent during the post-intervention phase. These were two independent samples.

During the pre-intervention period, all physicians who were to be involved in the PAC training completed the self-administered questionnaire; during the post-intervention period, all physicians who participated in PAC training responded to a similar questionnaire and also were interviewed.

\footnotetext{
${ }^{6} \mathrm{~A}$ PAC OR study conducted in Zimbabwe showed 42\% success rate for follow-up interviews at three months (Johnson et al., 1998). In Mexico, a study conducted in six hospitals in the IMSS in the Federal District demonstrated 44\% success rate at six-month follow-up (Fuentes Velásquez et al., 1998).
} 
Male partners were included in the arm of the study conducted in the Hospital "Jaime Sánchez Porcel." Of the 394 women interviewed in both the pre- and post-intervention phases, only 51 percent were accompanied by a male partner. Of these 201 women, 81 percent (163 women) agreed that their partner could be interviewed. ${ }^{7}$ All 163 men consented to be interviewed. Seven interviews were discarded leaving a total of 156 male partner interviews (86 pre-intervention, 70 post-intervention).

\section{Analysis of Data}

Data from all interviews conducted with women, men, and health care providers as well as observations of quality of care were captured. Univariate analysis was performed in order to calculate percentages, means and ranges relevant to the particular research question. Chi-square analysis for categorical variables and t-tests for continuous variables were calculated to determine significant differences between the two stages of the study in all hospitals. Significant differences are reported for results with a probability of $90 \%$ (p-value of less than or equal to 0.10 ). All calculations for determining time spent in the hospital and costs to the institution were carried out using Microsoft Excel.

\section{INTERVENTION}

The intervention introduced in each hospital consisted of training in the provision of PAC services, refresher trainings, and regularly scheduled supportive supervision visits to the services. Re-organization of PAC services was initially proposed as an important part of the project intervention as one way to decrease women's length of stay in the hospital. This was possible in two of the three study hospitals.

\section{Re-organization of $P A C$ services}

Re-organization of PAC services was finalized by the MSPS and Ipas in 1998 and 1999 prior to the initiation of the FRONTIERS project in the Maternidad Percy Boland. ${ }^{8}$ The emergency ward was refurbished and made into a labor and postabortion care area. Within

\footnotetext{
${ }^{7}$ The $19 \%$ of women who denied consent to interview the husband stated the following reasons: fear of being accused of provoking the abortion, fear of her partner's violent reaction, pregnancy from another man, pregnancy the result of rape, possible abandonment (especially among younger women), embarrassed about losing the pregnancy.

${ }^{8}$ Funding was provided by DFID, as part of their commitment to improving hospital services, including infrastructure, throughout the country.
} 
this new structure, ambulatory care was established and women were treated for incomplete abortion, whether with MVA or SC.

In the Hospital de la Mujer, workshop participants discussed the reorganization of services during the PAC training held in their hospital in August 1999 (see below) and mapped out the ways in which an existing area on the ground floor of the hospital could be refurbished. DFID funding was available for reconstruction of the area, which was finalized by the end of December 2000. As such, during the majority of the post-intervention phase of the FRONTIERS project, health care staff used this ground floor area to provide care to women treated with MVA, while women treated with SC continued to be hospitalized in the ob/gyn ward on the first floor. This patient flow is consistent with the definition of care and subsequent reimbursement offered to hospitals in the SBS health plan, whereby MVA is linked to ambulatory care and SC is linked to hospitalization (see section on Average Cost of Service Delivery).

PAC services in the Hospital "Jaime Sánchez Porcel” were not reorganized during the project such that women treated with MVA and SC for incomplete abortion continued to be hospitalized during the pre- and post-intervention periods. Funds were not available for refurbishment of another area of the hospital, and whether this was necessary, given the size of the hospital and the patient caseload, was a point of frequent discussion. By the end of the FRONTIERS project, ambulatory care for PAC patients still had not been established.

\section{PAC Training}

PAC training was accomplished through a five-day workshop based on a curriculum developed from Ipas's PAC training materials, which were reviewed and revised slightly in meetings among the MSPS, Ipas, Pathfinder and JHPIEGO. Didactic and clinical training sessions focused on three main areas and emphasized the responsibility of all health care providers in these areas:

- Humane care and ethics in PAC;

- Clinical practice: treatment of incomplete abortion with MVA, pain management during the uterine evacuation procedure, reuse of the MVA equipment; and 
- Communication, information and counseling: identification of women's needs and concerns, and information and counseling about the basic elements of PAC services (see Quality of Care Framework, Figure 1, page 11).

Thus, the training workshops highlighted and built upon many of the same themes emphasized in PAC projects developed during prior years and added components related to the use and re-use of MVA equipment. Sessions were attended by physicians, nurses, and at times social workers and psychologists from each of the hospitals.

A total of 78 health care providers participated in the core PAC training session held in each hospital (Table 1). The first PAC training workshop took place in the Hospital de la Mujer in August 1999 and was followed one week later by a workshop in the Maternidad Percy Boland. In La Paz, 25 professionals attended, including the hospital director and assistant director at the time, physicians, anesthesiologists, medical residents, nurses and one social worker. In Santa Cruz, 28 health care professionals attended the training sessions, including physicians, medical residents, nurses, one psychologist and one communications specialist. Twenty-four health professionals from the Hospital "Jaime Sánchez Porcel" and one physician from a nearby health center attended the training in order to initiate the process of improving referrals and counter-referrals.

Table 1. Number of health care providers participating in PAC training

\begin{tabular}{|l|c|c|c|c|}
\hline & $\begin{array}{c}\text { Hospital de la } \\
\text { Mujer }\end{array}$ & $\begin{array}{c}\text { Maternidad Percy } \\
\text { Boland }\end{array}$ & Hospital "JS Porcel" & Total \\
\hline $\begin{array}{l}\text { \# participants in } \\
\text { PAC training }\end{array}$ & 25 & 28 & 24 & 78 \\
\hline
\end{tabular}

PAC trainings held in La Paz and Santa Cruz were conducted by two Ipas Master Trainers (physician and psychologist), with the support of two Ipas Bolivia consultants- a physician and psychologist- who then became the core Bolivia-based Ipas PAC trainers. A Peruvian physician and midwife also participated in these two workshops in order to share their experience with participants. PAC training in the Hospital "Jaime Sánchez Porcel” took place in March 2000 and was conducted by Ipas Bolivia consultants, a physician and psychologist who had participated in the La Paz and Santa Cruz trainings, as well as a nurse who was one of the data collectors for the work conducted in the Hospital de la Mujer. 
During each PAC training, necessary equipment and supplies were donated to the hospital by Ipas so that shortages would not be a barrier to a timely initiation of PAC services. They included complete MVA kits, pain control medications to be used during the procedure, surgical clothing, and gloves. Providing the sites with start-up supplies was particularly important since many of the basic medications and supplies related to the procedure performed with MVA under local anesthesia were not included in the SBS procurement listing until the end of the FRONTIERS project.

In the Maternidad Percy Boland, Pathfinder International also conducted PAC training with personnel immediately after the Ipas training in August 1999. In November 1999, Pathfinder contracted a nurse from outside of the hospital to provide postabortion and postpartum contraceptive counseling services. A permanent position was never funded by the MSPS and the nurse left the hospital by June of 2000.

In each hospital, PAC trainers attempted to identify key personnel who would serve as advocates and site coordinators for the program. This process took a significant amount of time and by February 2001, a formal group of PAC coordinators was identified for each of the hospitals in which Ipas was working at the time. ${ }^{9}$

\section{Refresher Training}

Several refresher trainings were conducted by Ipas Bolivia staff in each of the three study hospitals subsequent to the original training in order to strengthen physicians' clinical skills using MVA and to improve communication practices, contraceptive counseling, and other information and counseling services. A psychologist conducted refresher trainings on communication and counseling, and a physician conducted clinical practice sessions. Focused refresher training on information and counseling was never conducted by Ipas in the Maternidad Percy Boland, despite repeated requests by Ipas to hospital administrators.

${ }^{9}$ PAC coordinators were named in the Hospital "Jaime Sánchez Porcel" and the Hospital de la Mujer and in other hospitals throughout the country where Ipas was working by the end of the year 2000. The Maternidad Percy Boland was not included due to decisions made by the MSPS to divide the responsibilities of Ipas and Pathfinder International by region and naming Pathfinder as the organization responsible for programs in Percy Boland, as well as other hospitals in designated areas, beginning in September 2000. 


\section{Supportive Supervision}

Supportive supervision visits were conducted by the same Ipas Bolivia training team, comprised of a psychologist and physician, every three to four months in each of the study sites. The visits took place after the core training and subsequent to refresher training sessions. A checklist structured their observations and written summaries. Their approach was one of engaging in supportive interactions with providers so that they could ask questions and improve their practices. Results from every visit were immediately shared with hospital directors, MSPS authorities and Departmental Health Services authorities (Servicio Departmental de Salud, SEDES) ${ }^{10}$ in order to engage them in ongoing discussions about the care being offered to women. Beginning in September 2000, supervision visits also were made by Pathfinder International rather than Ipas to the Maternidad Percy Boland, per decisions made by the MSPS (see footnote \#9).

\section{MAJOR FINDINGS}

Major findings are presented in a series of tables. The columns labeled "pre-" and "post-" refer to the pre- and post-intervention phases of the project. Data presented are derived from interviews conducted with women treated for abortion complications, questionnaires administered to physicians participating in the program, a review of hospital records, and observations related to the cost of service delivery. Results from observations documenting the quality of services were, in general, congruent with the results from interviews with women. Due to space limitations, these results are not presented in this report. In addition, since the intervention introduced in this project did not incorporate the role of male partners in postabortion care, only brief descriptions of findings from interviews are presented in the following sections.

\section{Women Included in the Study}

Over one-half of the women included in the study were between the ages of 20 to 30 years old, the majority were either married or cohabiting with a male partner, and most had some

\footnotetext{
${ }^{10}$ SEDES are responsible for the delivery and supervision of health services at the Departmental level.
} 
level of formal education. The greatest percentage of women in any of the samples (by hospital and study phase) identified themselves as housewives and few as professionals, while at the same time a significant proportion of women worked outside of the home (Table 2). Marginally significant differences between the pre- and post-intervention samples were found at a 0.10 level in women's educational level in the Hospital de la Mujer and the Maternidad Percy Boland. In both cases, women in the post-intervention sample were more educated than those in the pre-intervention sample. A marginally significant difference was also found in women's occupation in the Hospital "Jaime Sánchez Porcel”, where fewer women identified themselves as housewives in the postintervention phase.

Table 2. Percentage of women with selected socio-demographic characteristics

\begin{tabular}{|c|c|c|c|c|c|c|}
\hline \multirow[b]{2}{*}{$\begin{array}{c}\text { Phase of } \\
\text { Project }\end{array}$} & \multicolumn{2}{|c|}{ Hospital de la Mujer } & \multicolumn{2}{|c|}{ Maternidad Percy Boland } & \multicolumn{2}{|c|}{ Hospital "JS Porcel” } \\
\hline & $\begin{array}{c}\text { Pre } \\
(n=48)\end{array}$ & $\begin{array}{l}\text { Post } \\
(n=94)\end{array}$ & $\begin{array}{c}\text { Pre } \\
(n=116)\end{array}$ & $\begin{array}{c}\text { Post } \\
(n=283)\end{array}$ & $\begin{array}{c}\text { Pre } \\
(n=189)\end{array}$ & $\begin{array}{c}\text { Post } \\
(n=205)\end{array}$ \\
\hline Age & $\%$ & $\%$ & $\%$ & $\%$ & $\%$ & $\%$ \\
\hline 14- 19 years & 8 & 16 & 11 & 17 & 12 & 15 \\
\hline $20-25$ years & 33 & 36 & 46 & 41 & 41 & 41 \\
\hline $26-30$ years & 21 & 18 & 22 & 19 & 18 & 25 \\
\hline $31-44$ years & 38 & 30 & 22 & 23 & 29 & 19 \\
\hline Mean age & 29 & 26 & 26 & 26 & 27 & 26 \\
\hline Marital Status & & & & & & \\
\hline $\begin{array}{l}\text { Single } \\
\text { (never married) }\end{array}$ & 21 & 31 & 21 & 21 & 23 & 32 \\
\hline Married/ Cohab & 73 & 66 & 78 & 76 & 75 & 66 \\
\hline Sep/ Divorced & 4 & 3 & 1 & 2 & 2 & 1 \\
\hline Widowed & 2 & 0 & 0 & 1 & 0 & 1 \\
\hline Education $^{1}$ & & * & & * & & \\
\hline None & 13 & 18 & 27 & 17 & 30 & 25 \\
\hline Low & 60 & 37 & 48 & 52 & 29 & 25 \\
\hline Intermediate & 10 & 25 & 17 & 24 & 19 & 23 \\
\hline High & 17 & 20 & 8 & 7 & 22 & 27 \\
\hline Occupation & & & & & & * \\
\hline Housewife & 39 & 38 & 55 & 54 & 39 & 33 \\
\hline Employee & 26 & 16 & 21 & 25 & 13 & 20 \\
\hline Professional & 2 & 2 & 1 & 2 & 3 & 7 \\
\hline Student & 11 & 28 & 6 & 7 & 29 & 30 \\
\hline Other & 22 & 16 & 17 & 12 & 16 & 10 \\
\hline
\end{tabular}

Source: exit interviews with women treated for incomplete abortion

${ }^{1}$ None: never attended or did not complete primary school; Low: completed primary or did not complete secondary school; Intermediate: completed secondary school; High: preparatory school or more ${ }^{*}$ Pearson chi-square test, $\mathrm{p} \leq 0.10$, pre- vs. post-intervention 
Male partners included in the study (Sucre only) were, on average, 30 years of age (ranging from 18 to 54 years old). Fifty-nine percent had no or a low level of education, 12 percent finished secondary school, and 29 percent had high levels of education. Over threequarters of the men were workers or paid employees, with only 14 percent identifying themselves as students and 9 percent as professionals.

In general, across all samples, women's reproductive histories are comparable. Twentynine to thirty-eight percent of the women had experienced a previous abortion. The t-test indicates a significant difference for 'mean number of living children' among women in the Sucre pre- and post-intervention samples. Including the index pregnancy/abortion, women had on average, three to four pregnancies, one abortion, and two living children (Table 3).

Table 3. Reproductive history of women included in the study

\begin{tabular}{|l|c|c|c|c|c|c|}
\hline & \multicolumn{2}{|c|}{ Hospital de la Mujer } & \multicolumn{2}{c|}{ Maternidad Percy Boland } & \multicolumn{2}{c|}{ Hospital "JS Porcel" } \\
\hline $\begin{array}{l}\text { Phase of } \\
\text { Project }\end{array}$ & $\begin{array}{c}\text { Pre } \\
(\mathrm{n}=48)\end{array}$ & $\begin{array}{c}\text { Post } \\
(\mathrm{n}=94)\end{array}$ & $\begin{array}{c}\text { Pre } \\
(\mathrm{n}=116)\end{array}$ & $\begin{array}{c}\text { Post } \\
(\mathrm{n}=283)\end{array}$ & $\begin{array}{c}\text { Pre } \\
(\mathrm{n}=189)\end{array}$ & $\begin{array}{c}\text { Post } \\
(\mathrm{n}=205)\end{array}$ \\
\hline $\begin{array}{l}\text { Number of } \\
\text { pregnancies }\end{array}$ & & & & & & \\
Mean & 3.9 & 3.4 & 3.8 & 3.5 & 3.7 & 3.2 \\
Median & 4.0 & 3.0 & 3.0 & 3.0 & 3.0 & 2.0 \\
Range & $(1-11)$ & $(1-12)$ & $(1-13)$ & $(1-12)$ & $(1-15)$ & $(1-12)$ \\
\hline $\begin{array}{l}\text { Number of } \\
\text { abortions }\end{array}$ & & & & & & \\
Mean & 1.5 & 1.5 & 1.3 & 1.4 & 1.4 & 1.6 \\
Median & 1.0 & 1.0 & 1.0 & 1.0 & 1.0 & 1.0 \\
Range & $(1-3)$ & $(1-4)$ & $(1-7)$ & $(1-5)$ & $(0-8)$ & $(0-10)$ \\
\hline $\begin{array}{l}\text { Number of } \\
\text { living children }\end{array}$ & & & & & & \\
Mean & 2.2 & 1.8 & 2.5 & 2.2 & 2.5 & $1.9^{*}$ \\
Median & 2.0 & 1.0 & 2.0 & 2.0 & 2.0 & 1.0 \\
Range & $(0-8)$ & $(1-10)$ & $(0-11)$ & $(0-11)$ & $(0-13)$ & $(0-9)$ \\
\hline
\end{tabular}

Source: exit interviews with women treated for incomplete abortion

${ }^{1}$ Includes index pregnancy/abortion

${ }^{*}$ t-test for equality of means, $p=.025$, pre- vs. post-intervention

Table 4 illustrates the low levels of modern contraceptive use at any time prior to the most recent pregnancy ending in abortion among women in all of the samples. Over one-half of the women had never used any form of contraception at any time prior to their last 
pregnancy. Many responded that they did not do so because they did not know of a method $(13-31 \%)$ or because of their fears of side effects of contraceptive methods (14-30\%).

Of those who ever used a method, 50 percent to 84 percent were not using one when they became pregnant with the index pregnancy. Of those who had used a method, 19-35 percent of women across all samples discontinued use because they wanted to become pregnant.

Summarizing ever-use, approximately 25 percent to 50 percent of all women used the calendar rhythm method of natural family planning (NFP) to control their fertility. A high percentage $(38 \%)$ of the women from the Hospital de la Mujer used the IUD and an equal percentage of women from the Maternidad Percy Boland used the pill. The most prevalent reasons for discontinuing use were side effects of the method (28-32\%) or pregnancy while using a method (5-30\%).

Table 4. Ever use of modern contraceptive methods prior to pregnancy ending in abortion (\%)*

\begin{tabular}{|l|c|c|c|}
\hline & $\begin{array}{c}\text { Hospital de la Mujer } \\
(\mathrm{n}=142)\end{array}$ & $\begin{array}{c}\text { Maternidad Percy Boland } \\
(\mathrm{n}=398)\end{array}$ & $\begin{array}{c}\text { Hospital “JS Porcel” } \\
(\mathrm{n}=391)\end{array}$ \\
\hline Never used & $\%$ & $\%$ & $\%$ \\
Method used at & 65 & 51 & 51 \\
some time** & $(\mathrm{n}=50)$ & $(\mathrm{n}=196)$ & $(\mathrm{n}=192)$ \\
IUD & $\%$ & $\%$ & $\%$ \\
Pill & 38 & 13 & 12 \\
Injectable & 22 & 38 & 17 \\
Male Condom & 10 & 15 & 7 \\
Calendar rhythm & 16 & 7 & 49 \\
(NFP) & 28 & 33 & 50 \\
Not using at & & & \\
time of & 75 & 84 & \\
pregnancy & & & \\
\hline
\end{tabular}

Source: exit interviews with women treated for incomplete abortion

*"Use" refers to modern contraceptive use at any time prior to the current pregnancy ending in abortion

${ }^{* *}$ Sum of percentages may exceed $100 \%$ when women indicated use of more than one method

Table 5 gives some indication of the incidence of induced vs. spontaneous abortion among the women included in the study. Women indicating that they both planned and wanted the 
pregnancy ending in abortion as well as those who did not plan but wanted to be pregnant are likely to have experienced spontaneous abortion. The fact that a significant proportion of women said that they did not plan but wanted the pregnancy is supported by the explanation that many women offered that "once pregnant one should accept one's condition." Women denoting that they neither planned nor wanted the pregnancy are likely to have experienced an induced abortion.

Table 5. Percentage of women who planned and percentage of women who wanted the pregnancy that ended in abortion*

\begin{tabular}{|l|c|c|c|}
\hline & $\begin{array}{c}\text { Hospital de la Mujer } \\
(\mathrm{n}=135)\end{array}$ & $\begin{array}{c}\text { Maternidad Percy Boland } \\
(\mathrm{n}=388)\end{array}$ & $\begin{array}{c}\text { Hospital “JS Porcel” } \\
(\mathrm{n}=392)\end{array}$ \\
\hline $\begin{array}{l}\text { Planned and } \\
\text { wanted to be } \\
\text { pregnant }\end{array}$ & 28 & 20 & 34 \\
\hline $\begin{array}{l}\text { Did not plan } \\
\text { but wanted to } \\
\text { be pregnant }\end{array}$ & 19 & 43 & 29 \\
\hline $\begin{array}{l}\text { Did not plan } \\
\text { and did not } \\
\text { want to be } \\
\text { pregnant }\end{array}$ & 53 & \multicolumn{3}{|c|}{ Probably induced abortion } \\
\hline
\end{tabular}

Source: exit interviews with women treated for incomplete abortion

"Based on the questions "Did you plan this pregnancy?" and "Did you want to be pregnant?"

Results from the 3-month follow-up interviews with 269 women treated in the Hospital "Jaime Sánchez Porcel” (pre- and post-intervention) show that when compared to results from the exit interviews, women remained consistent in their responses regarding planning and wanting the pregnancy that was lost/aborted three months previously. When asked what they thought was the principal cause of the abortion, women provided a variety of responses, most commonly: from lifting heavy objects (31\%), ignoring the pregnancy (16\%), and suffering from a fall (14\%). A full 14 percent of women noted that they did not know and only 4 women of a total of 269 noted that the abortion was provoked/induced. Seven women $(3 \%)$ indicated that the abortion was the result of a forceful blow, without defining the source of the violence. 


\section{Quality of Care}

\section{Information and Counseling}

The results presented in Table 6 illustrate that most women reported that during their time in the hospital they were treated in a friendly manner by staff and they trusted the hospital staff attending to them, with significant improvements in the post-intervention group in the former found in Santa Cruz and Sucre, and significant improvements in the latter in La Paz and Santa Cruz. In general, however, staff did not introduce themselves to women, and the percentage doing so significantly decreased during the post-intervention period in the Hospital de la Mujer.

Relatively few women perceived that the staff identified the concerns that they had at the time when they entered the hospital. These included: concerns about their children, health status, fears of dying from complications, losing the pregnancy, loss of blood, what would be done to them in the hospital, and the uterine evacuation procedure.

Table 6. Women's perceptions of the support offered to them by hospital staff (\%)

\begin{tabular}{|c|c|c|c|c|c|c|}
\hline \multirow[b]{2}{*}{ Phase of Project } & \multicolumn{2}{|c|}{$\begin{array}{l}\text { Hospital de la } \\
\text { Mujer }\end{array}$} & \multicolumn{2}{|c|}{$\begin{array}{l}\text { Maternidad Percy } \\
\text { Boland }\end{array}$} & \multicolumn{2}{|c|}{$\begin{array}{l}\text { Hospital “JS } \\
\text { Porcel” }\end{array}$} \\
\hline & $\begin{array}{c}\text { Pre } \\
(n=48)\end{array}$ & $\begin{array}{c}\text { Post } \\
(n=94)\end{array}$ & $\begin{array}{c}\text { Pre } \\
(n=116)\end{array}$ & $\begin{array}{c}\text { Post } \\
(n=283)\end{array}$ & $\begin{array}{c}\text { Pre } \\
(n=189)\end{array}$ & $\begin{array}{c}\text { Post } \\
(n=205)\end{array}$ \\
\hline $\begin{array}{l}\text { Trusted hospital staff who attended } \\
\text { to her }\end{array}$ & 85 & 91 & 77 & $88^{*}$ & 75 & $86^{*}$ \\
\hline $\begin{array}{l}\text { Treated in a friendly manner by the } \\
\text { hospital staff }\end{array}$ & 83 & $93^{*}$ & 85 & $92^{*}$ & 98 & 97 \\
\hline Hospital staff introduced themselves & 29 & $7^{*}$ & 19 & 21 & 12 & 13 \\
\hline $\begin{array}{l}\text { Perceived that hospital staff } \\
\text { identified her concerns at the time } \\
\text { she entered the hospital }\end{array}$ & 44 & $6^{*}$ & 23 & $34^{*}$ & 23 & $12^{*}$ \\
\hline $\begin{array}{l}\text { Of women who perceived hospital } \\
\text { staff identified concerns: }\end{array}$ & $(n=21)$ & $(n=6)$ & $(n=27)$ & $(n=96)$ & $(n=43)$ & $(n=25)$ \\
\hline $\begin{array}{l}\text { Perceived that hospital staff helped } \\
\text { to address her concerns }\end{array}$ & 86 & $50^{*}$ & 78 & 83 & 83 & 84 \\
\hline
\end{tabular}

Source: exit interviews with women treated for incomplete abortion ${ }^{*}$ Pearson chi-square test, $p \leq 0.10$, pre- vs. post-intervention

Notably, providers' identification of such concerns decreased significantly from the pre- to the post-intervention phases in two of the three hospitals, while it increased in Santa Cruz. When health care providers did identify women's fears and concerns, the majority of 
women noted that providers helped to comfort them. Among the most important actions identified by women were providers speaking in a friendly and reassuring tone of voice, explaining what the care in the hospital would entail, and attending to women in a timely manner.

\section{Health Status}

Results in Table 7 show that over one-half of all women were informed about their health condition when they were first examined upon arrival at the hospital. Significant changes were not made in this practice during the two phases of the project. However, across all hospitals and during both the pre- and post-intervention phases of the project, fewer women were informed about their health condition subsequent to the uterine evacuation procedure, relative to those who were informed upon entering the hospital. Improvements in informing women about their health post-procedure were documented in Santa Cruz and Sucre, while a significant decrease was noted in La Paz.

Table 7. Percentage (\%) of women receiving information about health status

\begin{tabular}{|l|c|c|c|c|c|c|}
\hline & \multicolumn{2}{|c|}{$\begin{array}{c}\text { Hospital de la } \\
\text { Mujer }\end{array}$} & $\begin{array}{c}\text { Maternidad Percy } \\
\text { Boland }\end{array}$ & \multicolumn{2}{|c|}{$\begin{array}{c}\text { Hospital “JS } \\
\text { Porcel” }\end{array}$} \\
\hline Phase of Project & $\begin{array}{c}\text { Pre } \\
(\mathrm{n}=48)\end{array}$ & $\begin{array}{c}\text { Post } \\
(\mathrm{n}=91)\end{array}$ & $\begin{array}{c}\text { Pre } \\
(\mathrm{n}=116)\end{array}$ & $\begin{array}{c}\text { Post } \\
(\mathrm{n}=283)\end{array}$ & $\begin{array}{c}\text { Pre } \\
(\mathrm{n}=189)\end{array}$ & $\begin{array}{c}\text { Post } \\
(\mathrm{n}=205)\end{array}$ \\
\hline $\begin{array}{l}\text { Physician examining } \\
\text { women upon entry to the } \\
\text { hospital explained health } \\
\text { problem }\end{array}$ & 75 & 82 & 55 & 60 & 88 & 85 \\
\hline $\begin{array}{l}\text { Informed about health } \\
\text { status post-procedure }\end{array}$ & 37 & $26^{*}$ & 9 & $18^{*}$ & 24 & $37^{*}$ \\
\hline
\end{tabular}

Source: exit interviews with women treated for incomplete abortion

*Pearson chi-square test, $\mathrm{p} \leq 0.10$, pre- vs. post-intervention

Across both the pre- and post-intervention phases, only 38 percent of all male partners interviewed in the Hospital "Jaime Sánchez Porcel" received any information about the health status of their wife/partner, most commonly about the uterine evacuation procedure (97\%). Of the 97 men who were not informed at all about their partner's health status, 60 percent expressed that they would have like to have understood more, particularly about: the procedure, care for the woman after leaving the hospital, possible causes of the woman's health problem, ways of ensuring that the same problem does not happen again, and contraceptive methods. Overall, most men (80\% of total) had many remaining 
questions and concerns, including whether the woman would be able to be pregnant once again and about the overall consequences of the procedure or "operation."

\section{Uterine Evacuation Procedure}

All patients have a right to understand the risks and benefits of any medical procedure.

During the post-intervention phase, across almost all categories outlined in Table 8 a significantly greater percentage of women were informed about the different aspects of the uterine evacuation procedure, although overall a high proportion of women remained uninformed. Data not included in the table are that a marginally significant higher percentage of women treated with MVA (29\%) were informed about the instrument to be used during the procedure versus those who were treated with $\mathrm{SC}(5 \%)(\mathrm{p} \leq .10)$.

Table 8. Percentage (\%) of women whose attending physician explained aspects of the uterine evacuation procedure

\begin{tabular}{|l|c|c|c|c|c|c|}
\hline & \multicolumn{2}{|c|}{$\begin{array}{c}\text { Hospital de la } \\
\text { Mujer }\end{array}$} & $\begin{array}{c}\text { Maternidad Percy } \\
\text { Boland }\end{array}$ & \multicolumn{2}{|c|}{$\begin{array}{c}\text { Hospital "JS } \\
\text { Porcel" }\end{array}$} \\
\hline Phase of Project & $\begin{array}{c}\text { Pre } \\
(\mathrm{n}=48)\end{array}$ & $\begin{array}{c}\text { Post } \\
(\mathrm{n}=91)\end{array}$ & $\begin{array}{c}\text { Pre } \\
(\mathrm{n}=116)\end{array}$ & $\begin{array}{c}\text { Post } \\
(\mathrm{n}=283)\end{array}$ & $\begin{array}{c}\text { Pre } \\
(\mathrm{n}=189)\end{array}$ & $\begin{array}{c}\text { Post } \\
(\mathrm{n}=205)\end{array}$ \\
\hline $\begin{array}{l}\text { The procedure that would be } \\
\text { used to resolve the abortion }\end{array}$ & 53 & 49 & 36 & 42 & 20 & $29^{*}$ \\
\hline $\begin{array}{l}\text { The instrument that would } \\
\text { be used in the procedure }\end{array}$ & 0 & $12^{*}$ & 0 & $7^{*}$ & 0 & $26^{*}$ \\
\hline Procedural risks & 13 & 20 & 0 & $6^{*}$ & 4 & $20^{*}$ \\
\hline $\begin{array}{l}\text { Possible pain during the } \\
\text { procedure }\end{array}$ & 16 & $29^{*}$ & 0 & $15^{*}$ & 0 & $24^{*}$ \\
\hline $\begin{array}{l}\text { Steps taken to control pain } \\
\text { during the procedure }\end{array}$ & 56 & $41^{*}$ & 6 & $25^{*}$ & 3 & $23^{*}$ \\
\hline
\end{tabular}

Source: exit interviews with women treated for incomplete abortion

${ }^{*}$ Pearson chi-square test, $p \leq 0.10$, pre- vs. post-intervention

Results from follow-up interviews with women at three-months post-exit conducted in the Hospital "Jaime Sánchez Porcel” indicate that over time women continued to have questions about the success of the procedure. One-quarter of all women in both the preand post-intervention phases of the project expressed that they had lingering questions and doubts about the uterine evacuation procedure, most commonly thinking that the procedure was done poorly or would cause harm (48\%) and wondering whether something was left inside her body during the procedure (15\%). 


\section{Postabortion Contraceptive Services}

Table 9 illustrates that approximately one-half of all women in the study wanted to become pregnant once again, yet most preferred to wait up to one year or more before their next pregnancy. Combining the proportion of women who did not want to become pregnant once again (34\% to $62 \%)$ and those who stated that they want to space their next pregnancy results in a high percentage of women who have a need for contraceptive methods, both permanent and temporary.

Table 9. Percentage (\%) of women who want to space or limit future pregnancies

\begin{tabular}{|l|c|c|c|c|c|c|}
\hline & \multicolumn{2}{|l|}{ Hospital de la Mujer } & \multicolumn{2}{l|}{$\begin{array}{c}\text { Maternidad Percy } \\
\text { Boland }\end{array}$} & \multicolumn{2}{l|}{ Hospital “JS Porcel” } \\
\hline Phase of Project & $\begin{array}{c}\text { Pre } \\
(\mathrm{n}=48)\end{array}$ & $\begin{array}{c}\text { Post } \\
(\mathrm{n}=94)\end{array}$ & $\begin{array}{c}\text { Pre } \\
(\mathrm{n}=116)\end{array}$ & $\begin{array}{c}\text { Post } \\
(\mathrm{n}=283)\end{array}$ & $\begin{array}{c}\text { Pre } \\
(\mathrm{n}=189)\end{array}$ & $\begin{array}{c}\text { Post } \\
(\mathrm{n}=205)\end{array}$ \\
\hline $\begin{array}{l}\text { Limit future pregnancies/ Does } \\
\text { not want to be pregnant again }\end{array}$ & 52 & 60 & 62 & 52 & 56 & 34 \\
\hline $\begin{array}{l}\text { Desired timing of future } \\
\text { pregnancy }\end{array}$ & $(\mathrm{n}=23)$ & $(\mathrm{n}=38)$ & $(\mathrm{n}=44)$ & $(\mathrm{n}=136)$ & $(\mathrm{n}=83)$ & $(\mathrm{n}=135)$ \\
0 to 5 months & 4 & 9 & 14 & 5 & 10 & 7 \\
6 to 11 months & 11 & 3 & 29 & 15 & 13 & 2 \\
12 to 23 months & 30 & 31 & 14 & 16 & 12 & 7 \\
24 months or more & 37 & 50 & 36 & 55 & 53 & 69 \\
Don't know & 18 & 8 & 7 & 8 & 11 & 15 \\
\hline
\end{tabular}

Source: exit interviews with women treated for incomplete abortion

Despite the need for contraceptive services, results outlined in Table 10 show that few women in both phases of the project were informed that they could become pregnant once again before their next menstrual period, and few were asked about their plans for future pregnancy. Interesting results not shown in the table are that in the Maternidad Percy Boland, three to four times as many women treated with MVA verses those treated with SC during the post-intervention period were informed about the rapid return to fertility $(16 \%$ MVA vs. 4\% SC) and were asked about future plans to be pregnant again (28\% MVA vs. $10 \% \mathrm{SC})$. Relative to the pre-intervention period, these improvements are significant, as is the difference between women treated with MVA vs. SC. Such improvements are not attributed to the technology used per se but rather to the type of providers who use the different technologies. As noted below, medical residents tended to treat women with MVA while established physicians used SC most frequently in the Maternidad Percy 
Boland. Differences according to uterine evacuation technique were not documented in the other two hospitals.

Few women treated in the Hospital "Jaime Sánchez Porcel” (pre- and post-intervention) and the Hospital de la Mujer were asked if they wanted to receive a contraceptive method and in the latter this decreased significantly in the post-intervention phase. Results indicate ongoing problems with the linkage between emergency care services and contraceptive services in these two hospitals during the study periods. The linkage is stronger in the Maternidad Percy Boland, but also weakened significantly during the post-intervention phase. Another notable difference between the pre- and post-intervention phases in the Maternidad Percy Boland is that during the pre-intervention phase, almost all women $(90 \%)$ were presented with the option of the IUD as a contraceptive method to the exclusion of other methods. During the post-intervention phase, a greater percentage of women were presented with a wider range of contraceptive options.

Table 10. Percentage of women who received selected aspects of contraceptive services

\begin{tabular}{|l|c|c|c|c|c|c|}
\hline & \multicolumn{2}{|c|}{$\begin{array}{c}\text { Hospital de la } \\
\text { Mujer }\end{array}$} & \multicolumn{2}{c|}{$\begin{array}{c}\text { Maternidad Percy } \\
\text { Boland }\end{array}$} & \multicolumn{2}{c|}{ Hospital “JS Porcel” } \\
\hline Phase of Project & $\begin{array}{c}\text { Pre } \\
(\mathrm{n}=48)\end{array}$ & $\begin{array}{c}\text { Post } \\
(\mathrm{n}=94)\end{array}$ & $\begin{array}{c}\text { Pre } \\
(\mathrm{n}=116)\end{array}$ & $\begin{array}{c}\text { Post } \\
(\mathrm{n}=283)\end{array}$ & $\begin{array}{c}\text { Pre } \\
(\mathrm{n}=189)\end{array}$ & $\begin{array}{c}\text { Post } \\
(\mathrm{n}=205)\end{array}$ \\
\hline $\begin{array}{l}\text { Informed about rapid return to } \\
\text { fertility }\end{array}$ & 17 & $7^{*}$ & 3 & 7 & 4 & 6 \\
\hline $\begin{array}{l}\text { Asked about plans for future } \\
\text { pregnancy }\end{array}$ & 15 & 14 & 11 & 15 & 2 & $9^{*}$ \\
\hline $\begin{array}{l}\text { Asked if wanted to receive a } \\
\text { contraceptive method }\end{array}$ & 42 & $9^{*}$ & 63 & $53^{*}$ & 10 & 11 \\
\hline $\begin{array}{l}\text { Contraceptive methods presented } \\
\text { Injectable }\end{array}$ & $(\mathrm{n}=20)$ & $(\mathrm{n}=8)$ & $(\mathrm{n}=73)$ & $(\mathrm{n}=150)$ & $(\mathrm{n}=19)$ & $(\mathrm{n}=22)$ \\
IUD & 55 & 25 & 11 & 47 & 53 & 50 \\
Pill & 60 & 87 & 90 & 84 & 68 & 68 \\
Tubal Ligation & 55 & 12 & 21 & 44 & 58 & 50 \\
\end{tabular}

Source: exit interviews with women treated for incomplete abortion

${ }^{1}$ Multiple responses possible

${ }^{*}$ Pearson chi-square test, $p \leq 0.10$, pre- vs. post-intervention

Table 11 presents two important dimensions of postabortion contraceptive services in the three hospitals. Complementing Table 10, it illustrates that there was high unmet need for contraceptive services among postabortion women included in this study, in both the pre- 
and post-intervention phases. Only a small percentage of women received a contraceptive method before leaving the hospital in either the pre- or post-intervention phases, with a significant decrease post intervention in the Hospital de la Mujer and the Maternidad Percy Boland. High percentages (46\% to $87 \%$ ) of women across all samples indicated, however, that they would have liked to have received a contraceptive method.

Table 11. Percentage of women who received a contraceptive method or would have liked to have received a method prior to leaving the hospital

\begin{tabular}{|l|c|c|c|c|c|c|}
\hline & \multicolumn{2}{|c|}{$\begin{array}{c}\text { Hospital de la } \\
\text { Mujer }\end{array}$} & \multicolumn{2}{c|}{$\begin{array}{c}\text { Maternidad Percy } \\
\text { Boland }\end{array}$} & \multicolumn{2}{c|}{ Hospital “JS Porcel” } \\
\hline Phase of Project & $\begin{array}{c}\text { Pre } \\
(n=48)\end{array}$ & $\begin{array}{c}\text { Post } \\
(n=94)\end{array}$ & $\begin{array}{c}\text { Pre } \\
(n=116)\end{array}$ & $\begin{array}{c}\text { Post } \\
(n=283)\end{array}$ & $\begin{array}{c}\text { Pre } \\
(n=189)\end{array}$ & $\begin{array}{c}\text { Post } \\
(n=205)\end{array}$ \\
\hline $\begin{array}{l}\text { Received a contraceptive method } \\
\text { prior to leaving hospital }\end{array}$ & 17 & $2^{*}$ & 29 & $15^{*}$ & 0 & $3^{*}$ \\
\hline $\begin{array}{l}\text { Would have liked to have received a } \\
\text { method }\end{array}$ & 62 & 46 & 63 & 79 & 87 & 73 \\
\hline
\end{tabular}

Source: exit interviews with women treated for incomplete abortion

${ }^{1}$ Asked only of those women who did not receive a contraceptive method before leaving the hospital

${ }^{*}$ Pearson chi-square test, $p \leq 0.10$, pre- vs. post-intervention

For women leaving the Hospital de la Mujer and the Hospital "Jaime Sánchez Porcel" without a contraceptive method, the largest percentage noted that they did not do so because they did not receive any information about the options available to them. Fewer women noted this as a primary reason in the Maternidad Percy Boland. Interestingly, virtually no women emphasized the need to consult with their partners as a reason for not accepting a contraceptive method before leaving the hospital.

Of the 156 men interviewed in the Hospital "Jaime Sánchez Porcel," only 5 of them (3\%) received any information about contraceptive methods during their time in the hospital. Ninety-nine percent expressed their interest in finding out more about how to use different methods and what methods are available to them. A full 56 percent of all men noted that they and their partners would use a contraceptive method after leaving the hospital, 40 percent indicating use of an IUD and an equal percentage responding that they were not sure of which method to use.

\section{Summary results of three-month follow up interviews with women: Sucre}

Of the 269 women who participated in the 3-month follow-up interview (120 pre, 149 postintervention), 12 of them became pregnant within three months of leaving the hospital, 
according to self-reporting. All 12 women were pregnant at the time of the follow-up interview. Significantly fewer women were pregnant during the post-intervention phase relative to the pre-intervention phase (Table 12).

Table 12. Percentage (\%) of women pregnant during 3-month follow-up interview in Hospital "Jaime Sánchez Porcel”

\begin{tabular}{|l|c|c|}
\hline & \multicolumn{2}{|c|}{ Hospital “Jaime Sánchez Porcel” } \\
\hline Phase of Project & Pre $(\mathrm{n}=120)$ & Post $(\mathrm{n}=149)$ \\
\hline $\begin{array}{l}\text { Pregnant during time of follow-up } \\
\text { interview }\end{array}$ & $\begin{array}{c}7 \\
(9 \text { women })\end{array}$ & 2 \\
\hline
\end{tabular}

Source: 3-month follow-up interview with women

Pearson chi-square test, $p \leq 0.05$, pre- vs. post-intervention

None of the 12 pregnant women had received a contraceptive method prior to their exit

from the hospital yet only one had expressed the desire to be pregnant within 5 months after leaving the hospital. This same woman indicated that she had both planned and desired the pregnancy that ended in abortion for which she had been hospitalized three months earlier. Other women either did not want to be pregnant once again or wanted to space their next pregnancy over an extended period of time, once again highlighting missed opportunities to address unmet need for contraceptive services during women's stay at the hospital (Table 13).

Table 13. Women pregnant at time of 3-month follow-up interview: Number wanting to be pregnant and desired timing of future pregnancy

\begin{tabular}{|l|c|c|}
\hline Number of Women Responding & $\begin{array}{c}\text { Pre-Intervention } \\
(\mathrm{n}=9)\end{array}$ & $\begin{array}{c}\text { Post-Intervention } \\
(\mathrm{n}=3)\end{array}$ \\
\hline Wanted to be Pregnant Again & & 2 \\
Yes & 4 & 0 \\
No & 4 & 1 \\
Don't Know & 1 & $(\mathrm{n}=2)$ \\
\hline Desired Timing of Future & $(\mathrm{n}=4)$ & \\
Pregnancy & 1 & 0 \\
0-5 months & 1 & 0 \\
6-11 months & 0 & 0 \\
12-24 months & 2 & 2 \\
$>24$ months & & \\
\hline
\end{tabular}

Source: 3-month follow-up interview with women

Of the 257 women who had not become pregnant within three months after leaving the hospital ( $96 \%$ of total), 58 percent noted that they would like to be pregnant once again but $\mathrm{PAC}$ in the Bolivian Public Health System 
the majority (58\%) wanted to wait for at least 2 years. A full 42 percent stated at the threemonth interview that they did not want to become pregnant ever again.

Not one of the women included in the three-month follow-up sample during the preintervention period left the hospital with a contraceptive method; during the postintervention period one woman left with condoms and two left with an IUD inserted. Of these women, 42 percent (pre-intervention) and 50 percent (post-intervention) reported that they began to use a method within a few weeks after leaving the hospital. The majority employed the calendar rhythm method (38\%), followed by use of injectables $(24 \%)$, condoms (21\%), and IUD (12\%). Of those who used a modern contraceptive method, most obtained it from a pharmacy $(25 \%)$, a private physician $(21 \%)$, a family member $(17 \%)$, or the hospital where they had received care for abortion complications (16\%).

At the time of the three-month follow-up interview, a significantly greater proportion of women were using a contraceptive method during the post-intervention phase relative to the pre-intervention phase ( $48 \%$ vs. $3 \%)($ Chi-square $p=.000)$ (Table 14). During the postintervention phase, women obtained their method (in the case of modern methods) from the pharmacy $(25 \%)$, the hospital (24\%), a private physician $(22 \%)$, or a family member $(20 \%)$. It is noteworthy that the percentage of women who returned to the hospital to obtain a contraceptive method $(24 \%)$ was significantly higher $(\mathrm{p} \leq .05)$ during the post-intervention phase than during the pre-intervention period (8\%), reflecting an improved yet still inadequate linkage of treatment of abortion complications with postabortion contraceptive services.

Table 14. Percentage of women using a contraceptive method during the time of the 3-month follow-up interview

\begin{tabular}{|l|c|c|}
\hline & \multicolumn{2}{|c|}{ Hospital "Jaime Sánchez Porcel" } \\
\hline Phase of Project & Pre $(\mathrm{n}=69)$ & $\%^{*}$ \\
\hline Contraceptive method & $\%$ & 52 \\
None & 97 & 29 \\
Reversible modern methods & 0 & 1 \\
Tubal ligation & 0 & 19 \\
NFP: withdrawal or rhythm & 3 & \\
\hline
\end{tabular}

Source: 3-month follow-up interview with women

${ }^{*}$ Pearson chi-square test, $p=.00$, pre- vs. post-intervention 


\section{Care after Leaving the Hospital}

Information about the signs and symptoms of possible complications after leaving the hospital and about the re-initiation of sexual relations after returning home are two important areas that were not emphasized in the services provided to women, either pre- or post-intervention. Results shown in Table 15 highlight that in general less than 10 percent of women were told about the possibility of experiencing intense pain, bleeding for more than two weeks, fever, chills, or foul-smelling vaginal discharge, in which case they should seek further health care. Virtually no women were informed about when they could safely engage in sexual relations once again. There were no improvements made from the pre- to the post-intervention phases of the project, and in the case of the Hospital de la Mujer, services deteriorated. The only exception is that in all three hospitals significantly more women were given information about where to seek care in case of problems, but were not given information about what the possible problems might be.

Table 15. Percentage (\%) of women who received information about the signs and symptoms of possible complications after leaving the hospital, re-initiation of sexual relations and where to seek care in case of a problem

\begin{tabular}{|l|c|c|c|c|c|c|}
\hline & \multicolumn{2}{|c|}{$\begin{array}{c}\text { Hospital de la } \\
\text { Mujer }\end{array}$} & \multicolumn{2}{c|}{$\begin{array}{c}\text { Maternidad Percy } \\
\text { Boland }\end{array}$} & \multicolumn{2}{c|}{ Hospital “JS Porcel” } \\
\hline Phase of Project & $\begin{array}{c}\text { Pre } \\
(\mathrm{n}=48)\end{array}$ & $\begin{array}{c}\text { Post } \\
(\mathrm{n}=94)\end{array}$ & $\begin{array}{c}\text { Pre } \\
(\mathrm{n}=116)\end{array}$ & $\begin{array}{c}\text { Post } \\
(\mathrm{n}=283)\end{array}$ & $\begin{array}{c}\text { Pre } \\
(\mathrm{n}=189)\end{array}$ & $\begin{array}{c}\text { Post } \\
(\mathrm{n}=205)\end{array}$ \\
\hline Could have intense pain & 16 & $6^{*}$ & 0 & $4^{*}$ & 1 & 2 \\
\hline $\begin{array}{l}\text { Could have bleeding for more than } \\
\text { 2 weeks }\end{array}$ & 7 & 4 & 1 & 2 & 1 & $4^{*}$ \\
\hline Could have fever & 11 & $3^{*}$ & 0 & 2 & 2 & 1 \\
\hline Could have chills & 4 & 1 & 0 & 1 & 1 & 1 \\
\hline $\begin{array}{l}\text { Could have foul-smelling vaginal } \\
\text { discharge }\end{array}$ & 4 & 3 & 0 & 2 & 1 & 1 \\
\hline $\begin{array}{l}\text { When sexual relations could be re- } \\
\text { initiated }\end{array}$ & 7 & $1^{*}$ & 4 & 5 & 5 & 6 \\
\hline $\begin{array}{l}\text { Information about where to seek } \\
\text { care in case of a problem }\end{array}$ & 33 & $62^{*}$ & 2 & $14^{*}$ & 33 & $58^{*}$ \\
\hline
\end{tabular}

Source: exit interviews with women treated for incomplete abortion

${ }^{*}$ Pearson chi-square test, $p \leq 0.10$, pre- vs. post-intervention

None of the male partners who were interviewed at the Hospital "Jaime Sánchez Porcel" were given information about how to help with the woman's recovery after leaving the hospital. Yet all of the men stated at least one way in which they would support their partner after returning home. The most common responses included: help with the 
housework; ensure that she is resting and not taking on too much physical activity; feed her well; give her spiritual, economic and psychological support; and help her to care for the children.

\section{Appropriate Technologies and Clinical Performance}

Data from the clinical record forms indicate that after the training and supervision in PAC in the three hospitals included in the project, the incidence of problems or complications during the procedure, using either MVA or SC, was relatively low. Six of 192 (3\%) of women treated with MVA and 8 of 219 (4\%) of all women treated with SC experienced some sort of problem during the procedure, most commonly cervical laceration and low blood pressure. Equally, the occurrence of problems within the first few hours after the procedure was completed was relatively low in the post-intervention period: 3 of $192(2 \%)$ of women treated with MVA and 8 of 219 (4\%) women treated with SC. Problems included intrauterine bleeding, cervical bleeding and retention of products of conception. Uterine evacuation was complete in all women treated with MVA and in 216 of 218 (99\%) of all women treated with SC. No deaths of women treated for incomplete abortion were recorded in the three study hospitals during the project.

Subsequent to the intervention and after each physician had performed several procedures using MVA, interviews were conducted with 48 physicians in the three study hospitals who had participated in the program. Overall, they considered MVA to be more (49\%) or equally (36\%) safe when compared to $\mathrm{SC}$ for the treatment of incomplete abortion; equally ( $72 \%$ ) or more (26\%) effective; more (52\%) or equally ( $40 \%)$ simple to use; and that the use of MVA decreased the risk of procedural complications (83\%). The majority (94\%) of physicians noted that the use of MVA required a greater degree of interaction with the woman than when $\mathrm{SC}$ was used. This is attributed primarily to the use of pain control medications that allow the woman to remain conscious throughout the uterine evacuation procedure, in contrast to the use of heavy sedation or general anesthesia used for SC.

The main obstacles to the use of MVA for the treatment of incomplete abortion that were highlighted by the physicians interviewed in the project were: challenges related to pain 
management during the procedure (71\%), nursing staff not trained in the use and care of the MVA equipment, due to the frequent staff rotations (58\%), and the decision by women not to be conscious during the procedure $(56 \%)$.

Despite perceived barriers, high percentages of women were treated for incomplete abortion with MVA in the Hospital de la Mujer and Hospital "Jaime Sánchez Porcel," with a significant increase from the pre- to the post-intervention period. Physicians expressed increased satisfaction with their practice over time (See Table 16). MVA use remained steady and low in the Maternidad Percy Boland where physicians continued to use SC, stating that they did not have trained support personnel (nurses) to help them with the procedure, most importantly the reprocessing of the equipment. In addition, medical residents who rotated into the gynecology service of the hospital at different times during the project were the most enthusiastic users of MVA. According to observations and interviews with physicians, established obstetrician-gynecologists exhibited resistance to using the technology, feeling more adept with the use of SC, which they had been practicing for many years.

Table 16. Use of MVA and SC for the treatment of incomplete abortion: percentage of women treated with different clinical techniques ${ }^{1}$

\begin{tabular}{|c|c|c|c|c|c|c|}
\hline HOSPITAL & \multicolumn{2}{|c|}{ Hospital de la Mujer } & \multicolumn{2}{c|}{$\begin{array}{c}\text { Maternidad Percy } \\
\text { Boland }\end{array}$} & \multicolumn{2}{c|}{ Hospital “JS Porcel” } \\
\hline $\begin{array}{c}\text { Dates of } \\
\text { logbook review }\end{array}$ & $\begin{array}{c}\text { Jan - Dec } \\
2000 \\
(n=754)\end{array}$ & $\begin{array}{c}\text { Jan- June } \\
2001 \\
(n=474)\end{array}$ & $\begin{array}{c}\text { Jan - Dec } \\
2000 \\
(n=2532)\end{array}$ & $\begin{array}{c}\text { Jan - Mar } \\
2001 \\
(n=512)\end{array}$ & $\begin{array}{c}\text { Jan - Dec } \\
2000 \\
(n=582)\end{array}$ & $\begin{array}{c}\text { Jan - Mar } \\
2001 \\
(n=183)\end{array}$ \\
\hline MVA & 40 & $92^{*}$ & 15 & 15 & 68 & $75^{\star *}$ \\
\hline Sharp Curettage & 60 & 8 & 85 & 85 & 32 & 25 \\
\hline
\end{tabular}

Source: Review of hospital logbooks. All data, except Jan-March 2000 in the Hospital "Jaime Sánchez Porcel," were collected during the post-intervention period, after MVA was officially introduced into the hospitals. ${ }^{1}$ Uterine Size up to 14 Weeks

${ }^{*}$ Pearson chi-square test, $\mathrm{p}=.00$, pre- vs. post-intervention, ${ }^{* *} \mathrm{p}=.08$, pre- vs. post-intervention

Results presented in Tables 17, 18, and 19 illustrate pain control from the perspectives of both the physician performing the uterine evacuation procedure and the woman undergoing the procedure. Physicians' observations are limited to the uterine evacuation procedure alone, as captured in the clinical record form, while the information collected from women 
during the pre-exit interview relates to several stages of care during their time in the hospital.

Different medications were used across hospitals, even when the same clinical technique was employed. Most often, a combination of different medications was administered to control women's pain during the procedure. In the Hospital de la Mujer, Fentanyl was most commonly used during procedures using SC during the pre-intervention period (63\%) and Fentanyl (67\%) with Sodium Pentothal (71\%) during the post-intervention period; Lidocaine was used with 69 percent of women treated with MVA. Physicians in the Maternidad Percy Boland used a wide range of protocols and medications during all phases of the project, whether MVA or SC was used. Diazepam, Xilocaine 1\% and Klosidol were most often used with women treated with MVA, while Ketalar, Diazepam, and Atropine were most commonly administered to women treated with SC. Physicians in the Hospital “Jaime Sánchez Porcel” most often used Fentanyl along with SC and Xilocaine 1\% with women treated with MVA.

Overall, pain control was viewed as adequate and the women were considered comfortable during the procedure by the attending physician. In general, however, there was a significant difference in the responses of physicians when comparing MVA vs. SC use, in combination with different pain control protocols, during the post-intervention period.

Table 17. Pain control during the uterine evacuation procedure as reported by attending physicians

\begin{tabular}{|l|c|c|c|c|c|c|c|c|c|}
\hline & \multicolumn{2}{|c|}{ Hospital de la Mujer } & \multicolumn{2}{c|}{$\begin{array}{c}\text { Maternidad Percy } \\
\text { Boland }\end{array}$} & \multicolumn{2}{c|}{ Hospital "JS Porcel" } \\
\hline Phase of Project & Pre & \multicolumn{2}{|c|}{ Post } & Pre & \multicolumn{2}{c|}{ Post } & Pre & \multicolumn{2}{c|}{ Post } \\
\hline & $\begin{array}{c}\text { SC } \\
\mathrm{n}=24\end{array}$ & $\begin{array}{c}\text { MVA } \\
\mathrm{n}=53\end{array}$ & $\begin{array}{c}\mathrm{SC} \\
\mathrm{n}=24\end{array}$ & $\begin{array}{c}\mathrm{SC} \\
\mathrm{n}=91\end{array}$ & $\begin{array}{c}\text { MVA } \\
\mathrm{n}=42\end{array}$ & $\begin{array}{c}\text { SC } \\
\mathrm{n}=91\end{array}$ & $\begin{array}{c}\text { SC } \\
\mathrm{n}=183\end{array}$ & $\begin{array}{c}\text { MVA } \\
\mathrm{n}=96\end{array}$ & $\begin{array}{c}\mathrm{SC} \\
\mathrm{n}=96\end{array}$ \\
\hline $\begin{array}{l}\text { Pain control was } \\
\text { adequate } \\
\text { throughout the } \\
\text { procedure }\end{array}$ & 100 & 83 & $100^{*}$ & 99 & 87 & $99^{*}$ & 98 & 93 & $99^{*}$ \\
\hline $\begin{array}{l}\text { Patient perceived as } \\
\text { comfortable } \\
\text { throughout the } \\
\text { procedure }\end{array}$ & 97 & 77 & $100^{*}$ & 93 & 95 & 98 & 96 & 90 & $99^{*}$ \\
\hline
\end{tabular}

Source: clinical record forms

${ }^{*}$ Fisher exact 2-tailed, $\mathrm{p} \leq .05, \mathrm{MVA}$ vs. SC post-intervention 
As noted above, difficulties with pain management and the perception that women experienced more pain during a procedure performed with MVA were two areas identified as major barriers to the use of MVA by physicians in the post-intervention phase.

Table 18 presents women's reporting of pain throughout the process of care during the preintervention phase of the project. Most women reported feeling pain while waiting for the uterine evacuation procedure to take place. Virtually all women noted that they were unconscious during the uterine evacuation procedure and did not experience pain, in agreement with physicians' evaluation of pain control during the procedure. Over onequarter reported feeling pain immediately after the procedure in the Hospital de la Mujer and the Hospital "Jaime Sánchez Porcel" and over one-half in the Maternidad Percy Boland. A smaller percentage of women reported pain during the time of the interview, immediately prior to their exit from the hospital, than for other periods during which women were conscious.

Table 18. Percentage of women reporting experience of physical pain before, during and after uterine evacuation procedure and at time of interview: pre-intervention*

\begin{tabular}{|c|c|c|c|}
\hline \multicolumn{4}{|c|}{ Hospital de la Mujer (n=48) } \\
\hline $\begin{array}{c}\text { Immediately } \\
\text { before procedure }\end{array}$ & During procedure & $\begin{array}{c}\text { Immediately after } \\
\text { procedure }\end{array}$ & During interview \\
\hline 91 & 3 & 36 & 18 \\
\hline \multicolumn{4}{|c|}{ Maternidad Percy Boland (n=116) } \\
\hline 72 & 0 & 62 & 48 \\
\hline \multicolumn{4}{|c|}{ Hospital “Jaime Sánchez Porcel” (n=189) } \\
\hline 62 & 0 & 29 & 24 \\
\hline
\end{tabular}

Source: exit interviews with women treated for incomplete abortion

${ }^{*}$ All women treated with sharp curettage

The same general trend of women's reporting of pain is found among women treated during the post-intervention phase of the project, with both the use of MVA and SC (Table 19).

One important difference is that while women treated with SC were in general unconscious during the procedure and therefore reported no pain experienced at that time, a high percentage of women reported feeling pain during the procedure performed with MVA.

In the Hospital de la Mujer, 89 percent of women stated that the pain during the procedure was worse than they had expected, and 42 percent of them noted that they were supported 
by a health care provider to help them through the process. In the Maternidad Percy Boland, 54 percent of all women treated with MVA stated that the pain was worse than they had expected while 41 percent noted that it was less than they had expected. Over one-half $(60 \%)$ of all women were supported throughout the procedure by one or more staff from the hospital. Lastly, in the Hospital "Jaime Sánchez Porcel," 48 percent of all women treated with MVA reported that the pain during procedure was worse than they had expected and 39 percent noted that the pain was less than they had expected. Almost all $(93 \%)$ women treated in this hospital were supported by providers throughout the MVA procedure.

Table 19. Percentage of women reporting experience of physical pain before, during and after uterine evacuation procedure and at time of interview: post-intervention

\begin{tabular}{|c|c|c|c|c|c|c|c|}
\hline \multicolumn{7}{|c|}{ Hospital de la Mujer (MVA n=60, SC n=31) } \\
\hline $\begin{array}{c}\text { Immediately } \\
\text { before procedure }\end{array}$ & \multicolumn{2}{l|}{ During procedure } & \multicolumn{2}{|l|}{$\begin{array}{c}\text { Immediately after } \\
\text { procedure }\end{array}$} & \multicolumn{2}{|c|}{ During interview } \\
\hline MVA & SC & MVA & SC & MVA & SC & MVA & SC \\
\hline 78 & 65 & 91 & N/A & 50 & 39 & 8 & 10 \\
\hline \multicolumn{7}{|c|}{ Maternidad Percy Boland (MVA n=68, SC n=203) } \\
\hline MVA & SC & MVA & SC & MVA & SC & MVA & SC \\
\hline 54 & 71 & 86 & 3 & 43 & 28 & 21 & 14 \\
\hline \multicolumn{7}{|c|}{ Hospital "Jaime Sánchez Porcel” (MVA n=100, SC n=105) } \\
\hline MVA & SC & MVA & SC & MVA & SC & MVA & SC \\
\hline 91 & 88 & 93 & N/A & 36 & 32 & 7 & 6 \\
\hline
\end{tabular}

Source: exit interviews with women treated for incomplete abortion

\section{Average Cost of PAC Services}

Under the 1994 Bolivian Law of Popular Participation, local level authorities have a high level of responsibility and autonomy in attending to the needs of their communities. Local health funds are allocated from national tax revenues to and administered by municipal governments (alcaldias) and are the source of reimbursements to health facilities under the SBS. Reimbursement rates were determined by the MSPS and cover expenses related to drugs, supplies, hospitalization and laboratory exams included in the SBS plan. Personnel salaries and benefits are paid by the central government through representatives at the local 
level, while municipal governments cover capital costs Neither of these expenses are reimburseable (Dmytraczenko, 1998).

Reimbursement to hospitals when SC is used (and hospitalization is assumed) is 270 Bolivianos (US\$41.54) per procedure, which includes the estimated cost of two days of hospitalization. Reimbursement when MVA is used is 60 Bolivianos (US\$9.23) per procedure; no hospitalization is included. ${ }^{11}$ Of the total reimbursement per patient treated with MVA, approximately 38 Bs. is dedicated to "other expenses" in the SBS. The MSPS expects this latter amount to be used to purchase replacement MVA equipment, assumed to last for 500 procedures. $^{12}$

It is important to note that the results presented below are the average costs of service delivery, including medications, supplies, hospitalization, and personnel. These are not comparable to reimbursement rates under the SBS since the plan does not include labor costs. In addition, medications that are not included in the SBS basic procurement list are included in the calculations if they were used in women's care.

\section{Average Cost of Service Delivery to Hospitals (and Municipal Governments)}

The average cost of PAC services per patient to the institution was calculated by adding together several components of care during a woman's stay at the hospital:

- Average cost of medications and supplies used: cost of each item unit was obtained from the SBS Basic Procurement List and inventory lists from each hospital. Costs entered into the database were those of the actual quantity used throughout a woman's care.

- Average cost of using hospital space and infrastructure (ambulatory or in-patient carereferred to as 'hospitalization'): based on total annual operating costs of the hospital, the bed occupancy rate, and the cost per bed minute (linked to average length of stay).

- Average cost of personnel (includes salary and benefits): based on the amount of contact time with each patient and the annual salary and benefits of each personnel category.

The average length of stay (ALOS) of women in the hospital-including the time from admittance to discharge - decreased substantially from the pre-intervention period to the post-intervention MVA period (See Table 20). The decrease was smallest, yet still

\footnotetext{
${ }^{11}$ Exchange rate of 6.5 Bs. = \$US1.00. Ministerial Resolution 0182, May 10, 2001.

${ }^{12}$ By the end of the FRONTIERS project, MVA was placed on the SBS Basic Procurement List for hospitals PAC in the Bolivian Public Health System 
important, in the Hospital "Jaime Sánchez Porcel” where ambulatory services were not implemented during the project, indicating some role played by the introduction of MVA in shortening ALOS. Similar results were obtained in the Maternidad Percy Boland, where ambulatory service delivery was implemented for women treated with either MVA or SC. ALOS decreased for women treated with either technology between the two study periods, yet women treated with SC continued to remain in the hospital for, on average, 26 hours while those treated with MVA stayed for approximately four hours. The most important difference is seen in the post-procedure recovery time.

Table 20. Average time spent by women treated for incomplete abortion during each of care in hospital (hours)

\begin{tabular}{|c|c|c|c|c|c|c|c|c|c|}
\hline \multirow{3}{*}{ Phase of Project } & \multicolumn{3}{|c|}{ Hospital de la Mujer } & \multicolumn{3}{|c|}{$\begin{array}{c}\text { Maternidad Percy } \\
\text { Boland }\end{array}$} & \multicolumn{3}{|c|}{ Hospital “JS Porcel” } \\
\hline & \multirow{2}{*}{$\begin{array}{c}\text { Pre } \\
\text { SC } \\
n=37\end{array}$} & \multicolumn{2}{|c|}{ Post } & \multirow{2}{*}{$\begin{array}{c}\text { Pre } \\
\text { SC } \\
n=19\end{array}$} & \multicolumn{2}{|c|}{ Post } & \multirow{2}{*}{$\begin{array}{c}\text { Pre } \\
\text { SC } \\
n=97\end{array}$} & \multicolumn{2}{|c|}{ Post } \\
\hline & & $\begin{array}{l}\text { MVA } \\
n=30\end{array}$ & $\begin{array}{c}\mathrm{SC} \\
\mathrm{n}=22\end{array}$ & & $\begin{array}{l}\text { MVA } \\
n=51\end{array}$ & $\begin{array}{c}\mathrm{SC} \\
\mathrm{n}=30\end{array}$ & & $\begin{array}{l}\text { MVA } \\
n=54\end{array}$ & $\begin{array}{c}\mathrm{SC} \\
\mathrm{N}=47\end{array}$ \\
\hline Pre-Procedure & 4.84 & 2.19 & 22.39 & 3.57 & 1.72 & 3.35 & 5.95 & 3.47 & 7.45 \\
\hline Procedure & .70 & .64 & .89 & .70 & .52 & .67 & .90 & .71 & .77 \\
\hline Post-Procedure & 28.42 & 7.85 & 25.8 & 29.98 & 2.12 & 22.22 & 31.79 & 15.7 & 37.71 \\
\hline $\begin{array}{l}\text { Total Time in } \\
\text { Hospital }\end{array}$ & 33.96 & 10.68 & 49.08 & 34.25 & 4.36 & 26.24 & 38.64 & 19.88 & 45.93 \\
\hline $\begin{array}{l}\% \text { Change ALOS } \\
\text { (pre- to post) }\end{array}$ & N/A & $-68 \%$ & $+44 \%$ & N/A & $-87 \%$ & $-23 \%$ & N/A & $-48 \%$ & $+19 \%$ \\
\hline
\end{tabular}

Source: Observations of PAC services

The impact of introducing MVA and reorganizing services to ambulatory care on average cost of service delivery per patient is illustrated in Tables 21 and 22. The cost of medications and supplies remained fairly constant across time, hospitals and different clinical techniques, while personnel costs decreased in an important manner. There was also a dramatic decrease in the cost of hospitalization between the pre-intervention period and for those women treated with MVA during the post-intervention period. In the Hospital de la Mujer and the Hospital "Jaime Sánchez Porcel”, this cost actually increased during the post-intervention period when women were treated with SC.

Overall, the average cost of service delivery per patient decreased, with the most important savings seen with women treated with MVA. The exceptions were seen in the Hospital de la Mujer and the Hospital "Jaime Sánchez Porcel” where average cost of service delivery 
increased for women treated with SC. Where women continued to be hospitalized even when MVA was used, as was the case in the Hospital "Jaime Sánchez Porcel”, the decrease in cost from the pre-intervention period to the post-intervention MVA period is much lower than that seen in the other two hospitals. In addition, while ambulatory care was applied to all women in the Maternidad Percy Boland, the decrease in cost for women treated with MVA (-75\%) is much higher than for women treated with SC (-18\%).

Table 21. Average cost of per patient stay for PAC services (in \$US): pre-intervention project phase

\begin{tabular}{|l|c|c|c|}
\hline & Hospital de la Mujer & Maternidad Percy Boland & Hospital 'JS Porcel' \\
\hline & SC $(n=37)$ & SC $(n=19)$ & SC (n=97) \\
\hline $\begin{array}{l}\text { Personnel: salaries } \\
\text { and benefits }\end{array}$ & 11.59 & 11.28 & 12.59 \\
\hline $\begin{array}{l}\text { Medications and } \\
\text { supplies }\end{array}$ & 6.70 & 7.10 & 6.00 \\
\hline Hospitalization & 47.36 & 40.97 & 70.18 \\
\hline TOTAL & $\mathbf{6 5 . 6 5}$ & $\mathbf{5 9 . 3 5}$ & $\mathbf{8 8 . 7 7}$ \\
\hline
\end{tabular}

Source: Observations of PAC services

Table 22. Average cost of per patient stay for PAC services (in \$US): post-intervention project phase

\begin{tabular}{|l|c|c|c|c|c|c|}
\hline & \multicolumn{2}{|c|}{ Hospital de la Mujer } & \multicolumn{2}{c|}{$\begin{array}{c}\text { Maternidad Percy } \\
\text { Boland }\end{array}$} & \multicolumn{2}{c|}{ Hospital 'JS Porcel' } \\
\hline & $\begin{array}{c}\text { MVA } \\
(\mathrm{n}=30)\end{array}$ & $\begin{array}{c}\text { SC } \\
(\mathrm{n}=22)\end{array}$ & $\begin{array}{c}\text { MVA } \\
(\mathrm{n}=51)\end{array}$ & $\begin{array}{c}\text { SC } \\
(\mathrm{n}=30)\end{array}$ & $\begin{array}{c}\text { MVA } \\
(\mathrm{n}=54)\end{array}$ & $\begin{array}{c}\text { SC } \\
(\mathrm{n}=47)\end{array}$ \\
\hline $\begin{array}{l}\text { Personnel: salaries } \\
\text { and benefits }\end{array}$ & 5.92 & 9.86 & 4.56 & 9.68 & 6.58 & 9.00 \\
\hline $\begin{array}{l}\text { Medicines and } \\
\text { supplies }\end{array}$ & 4.10 & 4.50 & 5.90 & 7.50 & 6.00 & 6.10 \\
\hline Hospitalization & 14.90 & 68.48 & 5.21 & 31.38 & 36.16 & 83.49 \\
\hline TOTAL & $\mathbf{2 4 . 9 2}$ & $\mathbf{8 2 . 8 4}$ & $\mathbf{1 5 . 6 7}$ & $\mathbf{4 8 . 5 6}$ & $\mathbf{4 8 . 7 4}$ & $\mathbf{9 8 . 5 7}$ \\
\hline $\begin{array}{l}\text { \% Change in cost } \\
\text { (pre- to post) }\end{array}$ & $\mathbf{- 6 2 \%}$ & $\mathbf{+ 2 6 \%}$ & $\mathbf{- 7 5 \%}$ & $\mathbf{- 1 8 \%}$ & $\mathbf{- 4 5 \%}$ & $\mathbf{+ 1 1 \%}$ \\
\hline
\end{tabular}

Source: Observations of PAC services

Table 23 presents average costs of service delivery per patient when personnel costs are not included. These results provide practice-based figures that can be compared to the SBS reimbursement rates. In every case, except that of women treated with SC in Percy Boland, the estimated average cost presented below is higher than the reimbursement rates set in the SBS. 
Table 23. Average cost of per patient stay for PAC services (not including personnel costs) (in \$US): post-intervention project phase

\begin{tabular}{|l|c|c|c|c|c|c|}
\hline & \multicolumn{2}{|l|}{ Hospital de la Mujer } & \multicolumn{2}{l|}{$\begin{array}{c}\text { Maternidad Percy } \\
\text { Boland }\end{array}$} & \multicolumn{2}{c|}{ Hospital 'JS Porcel' } \\
\hline & $\begin{array}{c}\text { MVA } \\
(\mathrm{n}=30)\end{array}$ & $\begin{array}{c}\mathrm{SC} \\
(\mathrm{n}=22)\end{array}$ & $\begin{array}{c}\text { MVA } \\
(\mathrm{n}=51)\end{array}$ & $\begin{array}{c}\text { SC } \\
(\mathrm{n}=30)\end{array}$ & $\begin{array}{c}\text { MVA } \\
(\mathrm{n}=54)\end{array}$ & $\begin{array}{c}\text { SC } \\
(\mathrm{n}=47)\end{array}$ \\
\hline $\begin{array}{l}\text { Medicines and } \\
\text { supplies }\end{array}$ & 4.10 & 4.50 & 5.90 & 7.50 & 6.00 & 6.10 \\
\hline Hospitalization & 14.90 & 68.48 & 5.21 & 31.38 & 36.16 & 83.49 \\
\hline TOTAL & $\mathbf{1 9 . 0 0}$ & $\mathbf{7 2 . 9 8}$ & $\mathbf{1 1 . 1 1}$ & $\mathbf{3 8 . 8 8}$ & $\mathbf{4 2 . 1 6}$ & $\mathbf{8 9 . 5 9}$ \\
\hline $\begin{array}{l}\text { Difference: } \\
\begin{array}{l}\text { average cost - } \\
\text { reimbursement rate }\end{array}\end{array}$ & $\mathbf{\$ 9 . 7 7}$ & $\mathbf{\$ 3 1 . 4 4}$ & $\mathbf{\$ 1 . 8 8}$ & $\mathbf{- \$ 2 . 6 6}$ & $\mathbf{\$ 3 2 . 9 3}$ & $\mathbf{\$ 4 8 . 0 5}$ \\
\hline
\end{tabular}

Training costs also are important to take into consideration when introducing services or modifications in existing services. The cost of PAC with MVA five-day training workshops conducted by a non-governmental organization (Ipas Bolivia) varied according to related travel needs of both participants and instructors. The full cost for training in the Hospital "Jaime Sánchez Porcel”, for example, which required travel by some attendees and instructors, rental of a workshop space, honoraria, administrative time and materials for 25 health care professionals was approximately \$US10,000 or \$US 400 per participant.

These training costs were not included in the analysis, or they were treated as fixed costs, similar to the costs of upgrading facilities. The cost of training conducted by the MSPS or health care providers may be different and most likely will be lower when teams of PAC trainers exist throughout the country.

\section{Costs Incurred by Women Treated for Abortion Complications}

While the SBS aims to cover the full cost of treatment of women with incomplete abortion, women continued to pay for aspects of their care during both the pre- and post-intervention phases of the project. Despite the MSPS's objective to raise the level of knowledge among men and women about the services of the SBS, less than half of all women in all sites across the pre- and post-intervention phases had ever heard of the SBS. Of those women approximately 70 percent knew that PAC services were free. Thus, few women included in the study were fully informed about the coverage of their health care.

All women treated for abortion complications included in the study incurred some out-ofpocket expense for PAC services, during both the pre- and post-intervention phases of the 
project. During the presentation of project results in their sites, hospital directors and health care providers explained that the SBS did not fully cover all of the supplies and medications used in women's care, thus women had to purchase these items. For example, when MVA is used only Lidocaine, Fentanyl and Diazepam are covered in the SBS, yet in the Maternidad Percy Boland and the Hospital Jaime Sánchez Porcel, most physicians using MVA also used Xilocaine 1\% to control pain during the procedure. Women had to purchase Xilocaine from the pharmacy. This took place despite ample supplies provided by Ipas Bolivia subsequent to the PAC training, which often times remained in hospital storage areas.

Ultrasound was used with many women to verify that the uterine evacuation was complete and women were charged for this service. This was especially true in the Hospital de la Mujer and the Hospital "Jaime Sánchez Porcel” during the early phases of providers' use of MVA, when they did not feel fully adept with the technique. Information gathered during supervisory visits indicated that after a few months of using MVA providers usually were no longer using ultrasound to verify complete uterine evacuation.

\section{DISSEMINATION OF PROJECT RESULTS}

Project results were disseminated in various formats throughout Bolivia as well as in international settings.

- The bulletin series "Acciones en APA" with five titles, was distributed throughout Bolivia to health care providers, policymakers, universities and NGOs. It is available in the Spanish section of the Ipas website www.ipas.org:

(1) Implementando un modelo de atención de alta calidad, atención postaborto (Implementing a high quality PAC model);

- (2) La participación de la pareja masculina en el proceso de atención postaborto (Male participation in the PAC process);

- (3) Información y orientación: componentes claves del modelo de atención postaborto (Information and counseling: Key components of PAC);

(4) Servicios de anticoncepción postaborto: el segundo componente del modelo de atención postaborto (Postabortion contraceptive services: the second component of PAC);

- (5) Tratamiento de hemorragias de la primera mitad del embarazo: el uso de aspiración manual endouterina (AMEU) y legrado uterino instrumental (LUI) 
(Management of bleeding in the first half of preganacy: the use of MVA and $\mathrm{SC})$.

- IEC booklet to assist providers during PAC counseling and for women to take home with them.

\section{Report:}

- November 2000, Post-Image (consultants to Ipas), study and report for the production of IEC materials: Demandas y necesidades con respeto a material informatvo de preferencia de las mujeres atendidas por causas de hemorragias en la primera mitad del embarazo, en tres diferentes centros de salud.

\section{Presentations:}

- January 2001, Presentation of preliminary results to FRONTIERS and USAID staff, Washington DC.

- February 2001, Presentation of results in Maternidad Percy Boland. Presented by Ipas, USAID Bolivia and MSPS. Attended by hospital directors, staff, UNICEF representative, and local SEDES officials.

- March 2001, La Calidad de Servicios de Atención Postaborto en el Sector Público en Bolivia. Deborah L. Billings and Hugo Arévalo (Panel on Quality of Care), IX Congreso Nacional de Salud Pública, INSP, March 2001 in Cuernavaca, Mexico.

- April 2001, La Participación de la Pareja Masculina en el Proceso de Atención Postaborto (APA) en Bolivia. Deborah L. Billings, Hugo Arévalo (Panel on abortion care) and Implementación de un modelo de calidad de atención postaborto en Bolivia. Deborah L. Billings, Hugo Arévalo, Eliana Del Pozo (Poster), XVII Meeting of the Asociación Latinoamericana de Investigadores en Reproducción Humana, ALIRH, Curitiba, Brazil.

- June 2001, First PAC conference in Guatemala, Guatemala City, Organized by Population Council and CIESAR.

- August 2001, Presentation of results in Hospital de la Mujer. Presented by Ipas. Attended by hospital directors, staff, UNICEF representative, and local SEDES officials.

- August 2001, Presentation of results in Hospital "Jaime Sánchez Porcel”. Presented by Ipas and MSPS. Attended by hospital directors and staff.

- December 2001, Postabortion Care in University Curriculum: First National Conference of University Administrators, Faculty and Representatives from Medical and Nursing Schools: An Analysis of the Impact of Hemorrhage During the First Half of Pregnancy on Maternal Mortality (organized by Ipas Bolivia and the Executive Committee for Bolivian Universities (CEUB).

Dissemination of project results are planned for the future in the following formats:

Peer-reviewed journal submissions:

- Publication submission: Quality of care and PAC services in Bolivia 
- Publication submission: Men's involvement in PAC services. Lessons from Bolivia

- Publication submission: Pain control and PAC services (results will be combined with those from other PAC studies)

- Publication submission: Cost of PAC service delivery in Bolivia

Conference presentations:

- 2002 American Public Health Association

- 2002 National Institute of Public Health (Mexico)

Other

- Executive summary (in Spanish) of FRONTIERS final report to be distributed to health care providers, policymakers, universities, donors and NGOs throughout Bolivia

\section{CONCLUSIONS AND RECOMMENDATIONS}

The FRONTIERS PAC OR project described in this report made an important contribution to advancing the availability PAC services in Bolivia. It was carried out in response to the request made by the Ministry of Health in 1998 for a project that would help to guide their strategies and actions related to PAC services delivered in public hospitals throughout the country. The project was initiated at the same time that PAC was introduced as a service covered by the national-level Seguro Básico de Salud health plan. Reducing the cost of delivering services and improving the quality of care were the main areas of interest to the Ministry of Health.

Research, service delivery interventions and dissemination of project results were carried out in an intensive manner in three of Bolivia's most important maternity hospitals over the course of two years. During this same time, PAC training and supervision activities in other health facilities throughout the country were carried out by Ipas Bolivia and Pathfinder International. The combined efforts of multiple projects provided impetus for various advances made in Bolivia in a relatively short period of time, including opening new levels of discussion about the issue of postabortion care within the MSPS and among different NGOs; legitimizing PAC services as a core component of reproductive health care; building stronger ties and collaboration among organizations and institutions, mainly through the vehicle of CICAPA; publishing and disseminating the Norms and Procedures for Care of Hemorrhage During the First Half of Pregnancy through participation in a national level workshop; developing the first IEC pamphlet aimed at women treated for 
abortion complications; and paving the way for Ipas's PAC work now taking place at the district and primary levels of care.

\section{Quality of Care}

\section{Information and Counseling}

Health care providers must recognize that access to correct information is a right of all patients and that they are responsible for ensuring this right. They need to be committed to using the time that women spend in the hospital to offer them all the information that will assist them in making informed decisions throughout the process of care. Results from this project clearly show that the provision of basic information to women during their care for abortion complications is not emphasized as an important part of services and is not incorporated into the daily practice of health care providers when they attend to women. Despite refresher trainings and numerous supervision visits where these points were emphasized as important in service provision, problems continued during the project period. Overall, a clear pattern was documented whereby physicians focused their attention on the use of a new technology-MVA - while assuming that the responsibility for information and counseling was in the hands of nursing staff (see Rance 2000).

The intervention introduced into the three study hospitals generally had a positive effect on the information that women received about their health status after the uterine evauation procedure, about the uterine evacuation procedure itself, including possible risks and pain related to the procedure, steps that would be taken to control pain, and the instrument to be used. In this latter category, more women treated with MVA received information about the instrument than those treated with SC. The percentage of women who were informed about where to seek care in case of a problem after leaving the hospital almost doubled in each hospital during the post-intervention period, although women were not informed about what those problems might be. During the three-month follow-up interview with women in Sucre, over half had unresolved questions about their health status and whether the procedure had been done well.

Comments from numerous providers indicated that they did not have basic IEC materials that could help them to provide women with information. Thus, one of the main products from this project was the design and printing of a booklet that providers now can use with 
women throughout the process of care and that women can carry home with them. The material was produced in response to an expressed demand on the part of health care providers and women treated for abortion complications, but was done so during the final months of the project such that the effectiveness of its use could not be evaluated.

The project intervention was not successful in substantially improving postabortion contraceptive services delivered in the hospital prior to women's departure. During both the pre- and post-intervention phases of the project a high level of unmet need for contraceptive methods was documented among women prior to their departure from the hospital, highlighting missing linkages between emergency treatment of abortion complications and services that can help women to space or prevent future unwanted pregnancies.

However, results of the three-month follow-up interviews with patients treated in the Sucre hospital indicate that during the post-intervention period significantly more women were using a modern contraceptive method relative to those interviewed during the preintervention follow-up period, and almost one-quarter of those women had returned to the hospital to obtain their method. In addition, fewer women were pregnant at the time of the three-month interview during the post-intervention period. This suggests that in the Hospital "Jaime Sánchez Porcel” women still had to obtain methods at some point after leaving the hospital. Health care providers missed an important opportunity to ensure that women had necessary information and the method(s) they desired before returning to their homes.

These results differ from those of work carried out by Díaz and colleagues (Díaz et al., 1999) from 1995 -1997 in the same hospitals included in this study. Conclusions from the study state that contraceptive service delivery was improved when highly motivated staff were trained to improve their communication skills and to provide compassionate care, provided with continuous support from administrative and technical authorities, and were provided with refresher training and continuous supervision. Baseline results from the FRONTIERS project indicate that such improvements were not institutionalized or sustained. 
The discrepancies in the results from the two studies also can be attributed in part to differences in sources of data. The Díaz et al. study collected data from registers implemented within the hospitals, which hospital staff filled out each month to provide summary statistics on the number of women leaving the facility having received contraceptive counseling and a method. The FRONTIERS study reports data collected directly from interviews with women prior to their exit from the hospital. An evaluation of PAC services by Rance (2000) found that hospital registers often were filled out in an automatic fashion and service-related data differed from the accounts of women being discharged from the hospital.

Throughout the project, it was difficult to identify highly motivated staff to take the lead on linking contraceptive services with postabortion emergency treatment in the hospitals. In part this was due to several changes in the directorship of the Hospital de la Mujer, and the hiring of a nurse from outside of the hospital by Pathfinder International to take the lead on contraceptive service delivery in the Maternidad Percy Boland. Unfortunately, prior to her leaving the hospital she was not successful in transferring skills and responsibilities to other staff members. Nursing staff at the Hospital "Jaime Sánchez Porcel” commented on their heavy workload and no one person was designated as a leader to motivate and organize such services. In addition, continuous supervision conducted by a designated staff person or team with a constant presence in the hospital was not accomplished in the FRONTIERS project. Instead, supervision was realized through site visits conducted every three to four months to each of the project hospitals. It is clear that until such services are fully institutionalized into the regular practice of the hospital staff, periodic supervision and support is not sufficient.

Creative and committed leadership, both individual and in the form of interdisciplinary teams within the hospitals, is necessary to ensure that high quality PAC services are available to Bolivian women, particularly in the areas that remained weak by the end of the project: information and counseling of women related to their health status and care as well as contraceptive services. The PAC Coordinator group organized by Ipas and supported by the MSPS in the hospitals where Ipas continues to train and supervise services was 
convened toward the end of the FRONTIERS project and will have a positive impact on the development of such leadership.

\section{Appropriate Technologies and Clinical Performance}

One of the main areas of interest of the MSPS in this project was the introduction of MVA into the public sector for the treatment of incomplete abortion and linking this to the reorganization of services to ambulatory care. Training in the use of MVA and supervision in clinical practice resulted in a significant increase in the percentage of women treated with MVA for incomplete abortion in two of the three study hospitals. Its use remained relatively low throughout the project in the Maternidad Percy Boland, as medical residents adopted the technique, but established obstetrician-gynecologists continued to use SC.

Results show that MVA was used in a safe and effective manner by physicians. Those trained in the technique stated that it is an important option for the treatment of incomplete abortion, which decreases the risk of procedural complications and, when local anesthesia is used during the procedure, requires a greater degree of interaction with the woman being treated. The latter was seen both as a positive shift in patient care and as a challenge for attending physicians who noted difficulties with pain management, especially that women express the pain that they experience during the procedure. Physician skills in all aspects of pain management still need improvement.

\section{Cost of PAC Service Delivery}

Interventions carried out in the three project hospitals had a positive impact on reducing the cost of service delivery, most importantly because of the way in which patient flows were redefined in accordance with the definitions of care within the $S B S$. The impact of hospitalization vs. ambulatory care is clearly illustrated in women's ALOS. Important differences were found between women treated with MVA verses those with SC (in either the pre- or post-intervention phases of the project) in the Hospital de la Mujer and the Maternidad Percy Boland. Women cared for in the Hospital “Jaime Sánchez Porcel” with either MVA or SC throughout the project continued to be hospitalized due to claims that an ambulatory care area was not available. As a result, patient stay was longer and the average 
cost of service delivery was higher than in the other two hospitals during the postintervention period.

While the interventions introduced through this project did not address out-of-pocket expenses incurred by women treated for abortion complications, exit interviews documented that contrary to the $S B S$ plan, all women paid some amount of money for services throughout the project period. Most often women reported paying for medications, such as Xilocaine used during the uterine evacuation procedure, and laboratory services, such as ultrasound, not covered by the $S B S$. If women continue to need to pay for certain aspects of care, the goal of the MSPS to increase access to services may be hampered.

The PAC intervention made an impact in the introduction of new technology (MVA) and lowered the average cost of PAC service delivery. Overall, improvements were not made in the important area of information and counseling. Postabortion contraceptive services prior to women's departure from the hospital were not improved, despite the high unmet need for such services. Bolivia, because of its relatively late entry in the provision of comprehensive reproductive health services and official acceptance of family planning as an important public health intervention, is still in the early stages of putting in place a sustainable program.

Recent policy decisions and activities are a clear indicator of future achievements but to further this effort we have the following recommendations, derived from this project's experience.

\section{TRAINING AND SUPERVISION}

- New strategies for training need to be developed and tested since the intervention implemented in this project achieved very limited results in the area of information and counseling as well as postabortion contraceptive services. New training strategies to be tested could include initiating training and implementation of PAC with information and counseling components. When these have been solidly established, MVA training could follow. Pain management needs to continue to be a central element.

- In early stages of program implementation, continued on-the-job training needs to be included such that providers are accompanied by a supportive trainer who can model desired behaviors while trainees try new skills and behaviors. 
- Pre-service PAC training needs to become the norm in medical, nursing and social work school curricula.

- In addition, training and supervision capacity needs to be established in the MSPS and SEDES systems so that PAC can be part of the ongoing functioning of health programs throughout the country. The supervision work being conducted by JHPIEGO in health facilities can be key to this effort.

- Job aids and more IEC materials need to be developed to assist the MSPS in the implementation of the official PAC norms and guidelines.

- Continued technical and modest financial support needs to be provided to CICAPA and the PAC coordinator group. Coordinators should exist in all PAC programs.

- Enroll managers in health service sites at all levels of care as advocates and monitors of their assigned PAC responsibilities. These roles should include community information, referral and client follow-up at lower levels. This effort must involve donors and cooperating agencies.

- Develop in-house capacity to monitor programs and adopt a human rights and quality perspective to service delivery among technically specialized support organizations. Monitoring can entail modest periodic data collection from clients for program evaluation and continuous improvement at the local level.

\section{SUSTAINABILITY OF PAC SERVICES}

- Long-term sustainability will depend on institutional strengthening and will be facilitated if the MSPS can offer services without hidden, unexpected charges, to women. Hospital reimbursement must be a true reflection of costs incurred. Incentives could be developed for programs that demonstrate quality improvement and cost savings to the system. The present reimbursement scheme and definition of service provision within the SBS serve as strong disincentives to move toward ambulatory services for both SC and MVA.

- With women's prior consent, male partners should be involved in information and counseling processes since they may provide important support when women return to their homes. To be truly involved, women and men need correct information on health seeking behaviors and the benefits of contraceptive use.

- IEC efforts need to be reinforced to inform potential users of the services included in the SBS, including PAC services.

- Linkages between emergency care and contraceptive information and services need to be continuously improved. They must include the option for women to leave the hospital with a method of their choice and the information necessary to help achieve their reproductive goals in a healthful manner.

- Continue support of policy makers to further expand PAC services and to improve quality. This is particularly important after governmental or ministerial changes.

Finally, continued communication and collaboration between all stakeholders including Cooperating Agencies, NGOs, donors and the MSPS is needed for the dissemination of 
results from the FRONTIERS project and the incorporation of lessons learned in all PAC programs. 


\section{REFERENCES}

Arze PL and Del Pozo LE. 1998. Memorias del taller "Sensibilización y orientación sobre atención postaborto. La Paz, Bolivia, Ipas.

Benson J, Huapaya V, Abernathy M and King TDN. 1998. Improving quality and lowering costs in an integrated postabortion care model in Peru: final report. Lima, Peru, The Population Council and Ipas.

Centro Legal para Derechos Reproductivos y Políticas Públicas (CRLP), Oficina Jurídica para la Mujer. 2001. Derechos reproductivos de la mujer en Bolivia: un informe sombra. Cochabamba, Bolivia, CRLP.

Córdova J. 1997. Actitudes y opiniones sobre la tecnología Aspiración Manual Endouterina (AMEU). Estudio realizado con autoridades y proveedores de salud en servicios públicos de La Paz, Cochabamba y Sucre. La Paz, Bolivia, Ipas and MSPS.

Cornejo C. 1997. Personal communication in her role as Chief of National Unit of Care to Women and Children, Ministry of Health, Bolivia.

De la Gálvez Murillo A. 2000. Maternidad segura: carpeta informativa sobre la situación en Bolivia. La Paz, Bolivia, Comité por una Maternidad Segura.

Demographic Health Survey, Bolivia, 1998. Available online at www.measuredhs.com//; last accessed 4 October 2001.

Díaz J, Loayza M, de Yépez YT, Alvárez F, Lora O and Camacho V. 1999a. Evaluación de una estratégia para contribuir a mejorar la calidad de los servicios, incluyendo anticoncepción postaborto en tres hospitales de Bolivia. La Paz, Bolivia, MSPS, The Population Council, USAID.

Díaz J, Loayza M, de Yépez YT, Lora O, Alvárez F, and Camacho V. 1999b. Improving the quality of services and contraceptive acceptance in the postabortion period in three public-sector hospitals in Bolivia. In Dale Huntington and Nancy J. Piet-Pelon, eds. Postabortion care: lessons from operations research. New York, The Population Council.

Dmytraczenko T. 1998. Reducing maternal and child mortality in Bolivia. PHR Executive Summary Series. Bethesda, MD, Partnerships for Health Reform.

Domínguez S. 1999. Cuando el valor rompe el silencio: Crónica del primer aborto legal en Bolivia. Sucre, Bolivia, Centro Juana Azurduy.

Friedman A, De la Quintana C, Jové G and King TDN. 1999. An assessment of postabortion care (PAC) services in the Bolivian public health system: a report of research findings to the Ministry of Health and Social Welfare. Carrboro, NC, Ipas. 
Fuentes Velásquez J, Billings DL, Cardona Pérez JA and Otero Flores JB. 1998. A comparison of three models of postabortion care in Mexico: final report. Mexico City, IMSS, Ipas and The Population Council.

Greenslade FC, McKay H, Wolf M, and McLaurin K. 1994. Post-Abortion Care: A Women's Health Initiative to Combat Unsafe Abortion. Advances in Abortion Care, 4(1). Carrboro, North Carolina, IPAS.

Instituto Nacional de Estadística (INE). 1994. Encuesta nacional de demografía y salud, 1994. La Paz, Bolivia.

Johnson B, Mbizvo MT, Chipato T and Zawaira F. 1998. Conducting Follow-Up with Postabortion Women in Zimbabwe: Some Preliminary Descriptive Findings. Presented at the Global Meeting on Postabortion Care, New York, The Population Council.

Leonard A and Winkler J. 1991. A quality of care framework for abortion care. Advances in Abortion Care, 1(1):1-4. Carrboro, NC, IPAS.

Ministerio de Desarrollo Humano. 1994. Declaración de Principios sobre Población y Desarrollo Sostenible. La Paz, Bolivia.

Ministerio de Salud y Previsión Social (MSPS). 1999. Resolución Ministerial No. 0133 del 31 de Marzo de 1999. La Paz, Bolivia, MSPS.

Paxman JM, Rixo A, Brown L and Benson J. 1993. The clandestine epidemic: the practice of unsafe abortion in Latin America. Studies in Family Planning 24, 4 (July/August): 205226.

Rance, S. 2000. Ex-Post evaluation: Ipas project phase I (1996-1999), Improving the quality and availability of postabortion care services. La Paz, Bolivia, DFID.

Rance, S. 1999a. Trato humano y educación médica. La Paz, Bolivia, Ipas/MSPS/DFID.

Rance, S. 1999b. Humane treatment in postabortion care: the role of medical education. La Paz, Bolivia, Ipas, Ministry of Health, DFID.

Rance, S. 1997. Discursos médicos en torno al aborto: estudios de caso en contextos hospitalarios de los sistemas de salud pública y seguridad social. Unpublished research project report. La Paz, Bolivia, Ipas/Secretaría Nacional de Salud/DFID.

Rance S. 1994. Aborto en Bolivia, una realidad vigente. Noticias Aliadas. La Paz, Bolivia.

Unidad Nacional de Atención a Personas (UNAP). 2000. Pautas para la prestación de servicios de anticoncepción en el marco de la salud sexual y reproductiva. La Paz, Bolivia, MSPS, JHPIEGO, USAID. 
Unidad Nacional de Atención a las Personas (UNAP). 2001. Manual de normas y procedimientos técnicos para el manejo de las hemorragias de la primera mitad del embarazo. La Paz, Bolivia, Ipas y el Ministerio de Salud y Previsión Social.

Wolf M and Benson J. 1994. Meeting women's needs for post.abortion family planning. Report of a Bellagio Technical Working Group. Supplement, International Journal of Gynecology and Obstetrics, Vol 45.

World Bank. 1994. World development report. Oxford, Oxford Academic.

World Health Organization (WHO). 1994. Abortion: a tabulation of available data on the frequency and mortality of unsafe abortion. $2^{\text {nd }}$ ed. Geneva, WHO.

World Health Organization (WHO). 1995. Complications of abortion: technical and managerial guidelines for prevention and treatment. Geneva, WHO.

WHO/UNICEF. 1996. Revised 1990 estimates of maternal mortality: a new approach by WHO and UNICEF. Geneva, WHO. 


\section{APPENDIX A}

\section{Data collected in FRONTIERS Bolivia PAC OR}

\begin{tabular}{|c|c|c|c|}
\hline Instrument & Hospital de la Mujer & $\begin{array}{c}\text { Maternidad Percy } \\
\text { Boland }\end{array}$ & Hospital "JS Porcel" \\
\hline Pre-Intervention & July - August 1999 & July - August 1999 & Nov 1999 - Feb 2000 \\
\hline $\begin{array}{l}\text { Exit interview with } \\
\text { women }\end{array}$ & 48 & 116 & 189 \\
\hline Clinical record form & 45 & 110 & 189 \\
\hline Provider questionnaire & 13 & 27 & 62 \\
\hline $\begin{array}{l}\text { Quality of care } \\
\text { observation }\end{array}$ & 46 & 29 & 104 \\
\hline Cost observation & 45 & 19 & 104 \\
\hline $\begin{array}{l}\text { Exit Interview with male } \\
\text { partner }\end{array}$ & $\mathrm{N} / \mathrm{A}$ & N/A & 86 \\
\hline $\begin{array}{l}\text { 3-month post-exit } \\
\text { interview: women }\end{array}$ & $\mathrm{N} / \mathrm{A}$ & $\mathrm{N} / \mathrm{A}$ & $\begin{array}{c}\text { (February - May 2000) } \\
120\end{array}$ \\
\hline Intervention & Aug $1999-$ Oct 2000 & Aug 1999 - Sept 2000 & March - Sept 2000 \\
\hline Training Reports & Yes & Yes & Yes \\
\hline $\begin{array}{l}\text { Supportive Supervision } \\
\text { Reports }\end{array}$ & Yes & Yes & Yes \\
\hline Post-Intervention* & Nov 2000 - Jan 2001 & Oct - Nov 2000 & Oct 2000 - Jan 2001 \\
\hline $\begin{array}{l}\text { Exit interview with } \\
\text { women }\end{array}$ & 94 & 283 & 205 \\
\hline Clinical record form & 82 & 144 & 198 \\
\hline $\begin{array}{l}\text { Interview with } \\
\text { Providers: MVA use }\end{array}$ & 13 & 19 & 15 \\
\hline Provider questionnaire & 13 & 27 & 62 \\
\hline $\begin{array}{l}\text { Quality of care } \\
\text { observation }\end{array}$ & 58 & 91 & 111 \\
\hline Cost observation & 57 & 87 & 112 \\
\hline $\begin{array}{l}\text { Exit Interview with male } \\
\text { partner }\end{array}$ & N/A & $\mathrm{N} / \mathrm{A}$ & 70 \\
\hline $\begin{array}{l}\text { 3-month post-exit } \\
\text { interview: women }\end{array}$ & $\mathrm{N} / \mathrm{A}$ & $\mathrm{N} / \mathrm{A}$ & $\begin{array}{c}\text { (January-April 2001) } \\
149 \\
\end{array}$ \\
\hline
\end{tabular}

* Per the request of USAID/ Bolivia, Ipas conducted exit interviews with women in La Paz and Santa Cruz during November 1999. These data are not included in this report. 